\title{
Gap-accepteance parameters for roundabouts: a systematic review
}

\author{
Orazio Giuffrè $^{1}$ - Anna Granà ${ }^{1}$ - Maria Luisa Tumminello ${ }^{1}$
}

Received: 3 August 2015 / Accepted: 27 November 2015 / Published online: 7 December 2015

(C) The Author(s) 2015. This article is published with open access at SpringerLink.com

\begin{abstract}
Purpose The critical and follow-up headways are the two gap-acceptance parameters which explain the traffic interaction of a minor street vehicle when enters the roundabout, merging into or crossing one or more circulating (major) streams. Several studies and researches provide measurements of critical and follow-up headways from real data at roundabouts. The objective of our research is to synthesize the data from the series of selected studies to interpret variation across the studies.

Methods In order to match the research goal, a systematic literature review on estimations of critical and follow-up headways at roundabouts was undertaken. Since several studies and researches developed worldwide were examined, we were able to note that the effect size varied from study to study. Thus the meta-analysis of effect sizes was performed as part of the literature review through the random-effects model. Results After discussing the assumptions of this model, the dispersion in effects across studies was assessed and the summary effect for each of the parameters under examination was computed. Calculations were made both for single-lane roundabouts and double-lane roundabouts, as well as for turbo roundabouts.

Conclusions Compared to the results of individual studies, the single (quantitative) meta-analytic estimate provides an accurate and reliable synthesis on the specific issue here addressed, and gives, with greater power of the individual
\end{abstract}

Anna Granà

anna.grana@unipa.it

1 Department of Civil, Environmental, Aerospace, and Material Engineering Polytechnic School, University of Palermo, Italy, Viale delle Scienze, Ed 8, 90128 Palermo, Italy reviewed studies, a comprehensive measure for the parameters of interest.

Keywords Roundabouts · Critical headway $\cdot$ Follow up Headway $\cdot$ Systematic Review $\cdot$ Meta-analysis

\section{Introduction}

\subsection{The background}

In recent years, roundabouts have gradually gained great popularity worldwide as they represent a type of intersection control without traffic signals which, by making use of a circular geometric layout, establishes a self-regulated intersection control system. The vehicles entering the roundabout only conflict with vehicles coming from the immediate left since roundabouts accommodate traffic flow in one direction around a central island. Compared to all-way-stop-controlled intersections, roundabouts reduce speed as well as number of conflict points. However, the safety and operational performance of a roundabout is a product of its design [1,2]. At the planning stage, there are a variety of possible reasons and/ or goals for determining whether a roundabout is feasible, before expending the efforts required for further analysis and design [3]. When developing a more detailed design, in turn, the trade-offs of safety, capacity, cost, and so on must be identified and evaluated throughout the design process [4]. The process of designing roundabouts, more so than other intersection forms, requires a considerable amount of iteration among geometric layout, operational analysis, and safety evaluation; thus the designer often needs to revise and refine the initial layout attempt to enhance its capacity and safety $[2,5]$. While the basic form and features of roundabouts are uniform regardless of their location, the geometric design of a 
roundabout requires the balancing of competing design objectives. Many design parameters can be different depending on the speed environment, desired capacity, available space, and other geometric attributes proper at each individual (rural or urban) site, whereas many of the design techniques can be substantially different for single-lane roundabouts than for multi-lane roundabouts [2]. Alternative types of roundabouts, such as turbo roundabouts and flower roundabouts, are a fairly recent development and have only been implemented in a few countries to date $[6,7]$.

Capacity methods for two-way-stop-controlled intersections represent the starting point for evaluating operational performances at roundabouts. According to [8], entry capacity calculations at steady-state conditions can be performed through a variety of capacity formulas incorporating some information on the roundabout configuration, represented by the number of circle lanes and entry lanes $[9,10]$, or other formulas incorporating some aspects of the roundabout geometry in somewhat detailed way [11], as well as formulas incorporating, together with geometric aspects, the users' behavior through the critical and follow-up headways (see eg [12-14]). Relevant concepts on capacity models at roundabouts can be found in [2, 15-17]. When critical headway and follow-up headway are involved, capacity estimations are being performed by analytical gap-acceptance models [8]. The accuracy of capacity calculations at roundabouts largely depends on the accurate estimation of critical and follow-up headways [2]. Several studies have concluded that the maximum likelihood method is one of the most promising methods for estimating critical headway; general guidelines on how to apply the maximum likelihood methodology to measure critical headway have been already documented [18-20]. However, the critical headway estimated by such a method represents an average value of all the observed drivers. In turn, the follow-up headway value can be obtained from individual measurements; indeed, it can be measured for individual vehicles whenever two consecutive vehicles in a queue discharge from a minor stream. As a result, the capacity estimates based on the values of critical and follow-up headways also reflect average conditions. The same data of critical and follow-up headways included in the recent version of the Highway Capacity Manual [21] are average values representing a range of field data and site characteristics. Since most theories related to gapacceptance behavior, as employed for unsignalized intersections and roundabouts, presume that drivers are consistent and uniform, the capacity estimations are performed assuming constant values for the critical and follow-up headways, whereas these parameters, which are actually stochastically distributed, should be typically represented by a distribution of values.

According to [22] the effect that uncertainty in the input parameters has on the output results is a question that is not often considered in capacity analysis for roundabouts and, more in general, for unsignalized intersections. Indeed, an analyst provides a single number value for the critical headway and the follow-up headway which are used as input parameters for entry capacity estimations at roundabouts, without statement of a likely range of variation in the result. Several studies have documented that critical and follow-up headways might vary based on intersection geometry, vehicle type, approach grade, and traffic movements, so that more accurate estimates of these headways can be obtained based on specific conditions [18]. Kyte et al. [23] found that sitespecific data always yield superior forecasts compared to the forecasts using general values. Thus, the level of variability and uncertainty created by the critical and follow-up headways may be high and great difference in empirical sitespecific estimations of these gap-acceptance parameters can be found. As empirical evidence suggests, the quantification of the critical and follow-up headways can also vary based on the number of lanes, the diameter of the central island, the entry width, the presence (or not) of bunched vehicles in the circulating (major) streams, whereas at multi-lane roundabouts, the different demand scenarios can produce dominant and subdominant arrival flows at entries which in their turn can influence the predictions of the gap acceptance parameters $[24,25]$. Analysts know that there is variability in input data and overlook what is the impact of the uncertainty on capacity analysis $[26,27]$.

\subsection{Research aims and specific objectives of the paper}

This paper presents a systematic literature review of empirical studies and researches developed worldwide with the objective to measure the major parameters for gap-acceptance namely the driver's critical headway and the follow-up headway - using data collected in the field at existing roundabouts. It allowed us to summarize and evaluate the state of knowledge or practice on measuring critical and follow-up headways at single-, multi- and turbo roundabouts both installed in countries with a long-standing tradition on roundabouts (and turbo-roundabouts are already in operation), and realized in countries where in more recent times these circular schemes of intersections are becoming common as intersection control. This review of existing knowledge represented for us a preliminary step in a larger research activity aimed at summarizing in some way the collective results and exploring the presence or not of heterogeneity among the examined studies.

To do this, we sorted the results of the examined studies into categories based on what the existing studies, researches and published reports had in common, what the studies disagree about, and what they overlooked or ignored [28]. Thus, in order to reach a judgment about the quality of the literature overall, only the studies having the findings that appeared to be valid for the complete information in terms of average values of critical and follow-up headways (with the 
corresponding values of variance) and sample size were considered. An alternative approach to the traditional (simple) literature review was then performed through a process of synthesizing the data from a group of studies selected among the separate studies which were collected systematically as above specified.

In other words, a meta-analysis of effect size for each study, namely a statistical and quantitative analysis of the individual studies, was implemented as part of the literature review to assess the consistency of the effect across studies and to compute the summary effect [29]. This summary effect was searched for helping advance our specific interests about roundabouts and for designing further research on entry capacity estimations at roundabouts.

Beginning in the mid 1980s and taking root in the 1990s, researchers in many fields have been moving away from the narrative review, and adopting systematic reviews and metaanalysis [29]. These approaches are usually preferred since they offer an accurate and reliable summary on a specific issue and provide, with greater power of the individual reviewed studies, comprehensive measures, more accurate and reproducible, for the parameters of interest through statistical techniques to synthesize the data from the reviewed studies into a single quantitative estimate or summary effect size [29]. Several applications of meta-analysis have been carried out in the field of education, social science, biomedical studies, business and even ecology; in the last case, meta-analyses are being recently used to identify the environmental impact of treatments, the reactions to global climate change, the effectiveness of conservation management interventions, the implication of fuel consumption [30].

This paper is designed as follows. Based on the above starting point, the systematic literature review on worldwide studies incorporating estimations of critical and follow-up headways at roundabouts will be presented in next section 2 . After a brief introduction to the meta-analysis principles and the models on which the meta-analysis is based on (namely the fixed-effect model and the random-effects model), the statistical approach performed to synthesize the best available empirical data of critical and follow-up headways will be described in section 3; the same section presents the results of the meta-analysis. Conclusions will be presented in section 4 .

\section{Literature review on critical and follow-up headway estimations at roundabouts}

For the estimation of critical and follow-up headways from observations at roundabouts, a long series of methods has been proposed. Based on the considerations described above, a literature review on critical and follow-up headway estimations at roundabouts is presented. Focus is made on studies which have addressed the problems of how to manage the randomness and the variability of values of critical and follow-up headways, and how to depict the distribution of these gap acceptance parameters.

Without expecting to be exhaustive, studies and researches developed worldwide have been examined, with reference to the countries (as European countries and Australia) where the roundabouts have an older tradition and schemes of turboroundabouts are already in operation. Reference is also made to non-European countries where in more recent times roundabouts are becoming more and more common as intersection control and great emphasis has been given to geometric design and the appropriate use of the many roundabout installations progressively realized.

The reader should be aware that UK and French studies were excluded from our investigation despite the important role of the experiences of these countries on improving the roundabout installations [11, 12]. Experiences in Great Britain [11] were based on a capacity formula which is not a gap acceptance-based model, but the geometric design only is taken into account at a reasonable level of detail. In turn, the French procedure for capacity calculations at roundabouts is based on the exponential regression technique [12]; in this case, it is necessary to determine some geometric values of the roundabout and to use a pre-fixed value of the follow-up headway to implement the formula. Bearing in mind the inclusion criteria that we established for the analysis (see next section 3), French and UK experiences on roundabouts are not introduced in this literature review on critical and follow-up headway estimations at roundabouts. It refers to the most reliable literature for further study; among the books most accredited Mauro [8] is cited both for the illustration of the most important procedures currently used to calculate capacity at roundabouts and for the various issues that the calculation of roundabouts requires.

\subsection{European studies}

\subsubsection{German studies}

The capacity of roundabouts has been studied over many years by a series of investigations in Germany where for all types of modern roundabouts, except the mini, the capacities of entries have been established as independent from the flow at the other entries [31]. Although both gap acceptance theory and the empirical regression method have been in the scope of these investigations, Brilon [31] affirmed that the currently established official procedure in the German Highway Capacity Manual [32] is related to gap acceptance theory and uses Tanner's equation [33] in a form which was adjusted to the necessities of roundabout analysis [9, 34]. In order to ease capacity calculations, the computer program KREISEL, which can also apply capacity calculation procedures as they are reported from many other countries, is in frequent use [35]. 
According to Brilon [36], the values of critical, follow-up and minimum headways at single-lane roundabouts are depending on the inscribed circle diameter ranging from $26 \mathrm{~m}$ to $40 \mathrm{~m}$, whereas for multi-lane roundabouts the values of the behavioral parameters could be derived from the capacity formulas calibrated to German traffic conditions. Table 1 shows the minimum and maximum values of the mean critical headway derived from equations proposed by Brilon [36], where the inscribed circle diameter was set equal to $14 \mathrm{~m}$ and $40 \mathrm{~m}$, respectively. Within these values of the inscribed circle diameter we could recognize the mini and the compact roundabouts as classified by several international guidelines. The same table shows the minimum and maximum values of the mean follow-up headway; similarly, the minimum headway values resulted ranging from $2.04 \mathrm{~s}$ and $2.90 \mathrm{~s}$.

$\mathrm{Wu}$ [37] proposed the values of the critical, follow-up and minimum headways to be introduced in the formula for the entry capacity of a roundabout (see Tables 1 and 2); these parameters have been found to represent driver behavior at roundabouts in Germany and used in the recent edition of German HCM [36]. Wu [38] also estimated the distribution function of critical headways at unsignalized intersections based on equilibrium of probabilities; thus, he presented a solution accounting for different predefined distribution functions of critical headways. To carry out regression analysis, the form of the function was specified; thus, the log-normal distribution and the Weibull distribution were calibrated to the empirical distribution of critical headways. However, the Weibull distribution gave the best results in representing the distribution of critical headways.

Brilon et al. [39] proposed a framework for capacity estimation at turbo-roundabouts entries. Table 3 shows the values of the behavioral parameters depending on the scheme of conflict with one or two circulating streams; the same table shows the mean values of the critical headways for left and right lanes from major entries, where entering vehicles are faced by one circulating stream, and from minor entries, where entering vehicles are faced by two circulating streams.

\subsubsection{Swiss studies}

An extensive field data collection at 15 double-lane roundabouts with high traffic volume and different geometric characteristics provided a rich database for the analysis of the behavioral parameters [40]. Based on the observations of 2013 gap times of 16 entries, the critical and the follow-up headways were estimated. The maximum likelihood method $[19,41]$ was applied to measure driver's critical headways; the logarithmic normal distribution was used as mathematical function for the statistic distribution of these parameters. In turn, follow-up headways were determined with the arithmetic mean of the gap times, which were used for a subsequent entry in the roundabout. The minimum and maximum values of the mean critical and follow-up headways are summarized in Table 2. It should be noted quite large differences among the values of the critical headways ( $3.22 \mathrm{~s}$ for the minimum value and 4.33 for the maximum value), whereas the variability in the measured values of follow-up headway is kept small (about $0.5 \mathrm{~s}$ ).

\subsubsection{Danish studies}

In a Danish study aimed at estimating entry capacity and delay, a double-lane roundabout in Copenhagen, Denmark, was investigated; data were collected to enables the estimation of critical and follow-up headways [42]. Mean values of critical headways were estimated by using the maximum likelihood methodology [19] for the left- and the right-lane at entries (see Table 2). Critical headway estimates were provided for different levels of circulating flows (low, medium and high) and for the overall circulating flow. Moreover, in the case of the overall circulating flow, the mean critical headways for the leftlane at entries resulted higher than the mean critical headways for the right-lane. Estimations of the critical headways were performed also when the headway distributions in each circulating lane were considered separately. Thus critical headways were also distinguished for the inner- and outer circulating lane; for each entry lane, the values of critical headways for the inner circulating lane resulted lower than the corresponding values for the outer circulating lane, whereas the standard deviation showed the opposite trend. However, in all cases Hagring [42] observed that the values of critical headways resulted stable, from a minimum value of $3.68 \mathrm{~s}$ to a maximum of $4.68 \mathrm{~s}$, with a spread of slightly over a second for the various lanes and circulating flow combinations. Follow-up headways were also estimated both considering different types of vehicles (cars and heavy vehicles), and considering all vehicles. Table 2 shows the all vehicles-related values of follow-up headways. It should be noted that follow-up headways did not vary appreciably by entry lane, but there was a noticeable difference between cars and heavy vehicles; however, the sample size for heavy vehicles resulted small, and did not lead itself to statistical testing. Further investigation was conducted in Denmark [43]; based on field measurements, estimations of critical and follow-up headways were done (see Table 2).

\subsubsection{Dutch studies}

Further investigation by Fortuijn [44] covered several types of roundabouts in The Netherlands. An extensive traffic data collection formed the basis for the calibration of gap acceptance parameters for capacity models. Critical headways were derived from the difference between the accepted and rejected gaps. A maximum likelihood approach based on the assumption that the critical headway distribution is log-normal gave 
Table 1 Critical and follow-up headways values for single-lane roundabouts

\begin{tabular}{|c|c|c|c|c|c|c|c|c|c|c|}
\hline \multirow[t]{3}{*}{ study name } & \multirow[t]{3}{*}{ country } & \multirow[t]{3}{*}{ estimation method applied } & \multicolumn{4}{|c|}{ critical headway } & \multicolumn{4}{|c|}{ follow-up headway } \\
\hline & & & \multicolumn{2}{|c|}{ mean $[\mathrm{s}]$} & \multicolumn{2}{|c|}{ st. deviation $[\mathrm{s}]$} & \multicolumn{2}{|c|}{ mean $[\mathrm{s}]$} & \multicolumn{2}{|c|}{ st. deviation $[\mathrm{s}]$} \\
\hline & & & $\min$ & $\max$ & $\min$ & $\max$ & $\min$ & $\max$ & $\min$ & $\max$ \\
\hline Abrams et al. [73] & US & R.M. & 2.20 & - & - & - & - & - & - & - \\
\hline Brilon $[31,36]$ & Germany & n.a. & 4.07 & 4.45 & - & - & 2.89 & 2.99 & - & - \\
\hline Dahl \& Lee [75] & Canada & R.M., P.E. & 3.90 & 5.30 & - & - & 2.10 & 4.20 & - & - \\
\hline Fortuijn [44] & The Netherlands & n.a. & 3.16 & 3.28 & 0.19 & 0.28 & 2.10 & - & - & - \\
\hline Gazzarri et al. [45] & Italy & M.L.M. & 3.54 & 4.10 & 0.67 & 0.95 & 2.52 & 2.76 & 0.68 & 0.90 \\
\hline Mensah S. et al. [74] & US & n.a. & 2.50 & 2.60 & - & - & - & - & - & - \\
\hline Nicolosi et al. [49] & Italy & M.L.M., E.R.M. & 3.19 & 3.99 & 1.13 & - & 3.15 & 2.11 & 0.59 & - \\
\hline Qu X et al. [69] & Australia & n.a. & - & - & - & - & 2.76 & - & 0.62 & - \\
\hline Rodegerdts et al. [61] & US & M.L.M. & 3.90 & 5.90 & 0.70 & 1.80 & 2.60 & 4.30 & 0.80 & 1.50 \\
\hline Vasconcelos et al. [53] & Portugal & R.M., M.L.M., L.M., W.M., P.M. & 3.23 & 4.50 & - & - & - & - & - & - \\
\hline Vasconcelos et al. [55] & Portugal & R.M., M.L.M., E.R.M., L.M., W.M. & 3.37 & 4.28 & - & - & 2.08 & 2.20 & - & - \\
\hline $\mathrm{Wu}[37]$ & Germany & n.a. & 4.12 & - & - & - & 2.88 & - & - & - \\
\hline Xu \& Tian [72] & US & M.L.M. & 4.50 & 5.30 & 0.90 & 1.10 & 2.30 & 2.80 & 0.30 & 1.00 \\
\hline Zheng et al. [17] & US & M.L.M. & 3.80 & 5.50 & 1.00 & 2.00 & 2.30 & 3.80 & 1.00 & 2.60 \\
\hline
\end{tabular}

Note: R.M = Raff's method [47]; P.E. = Probability Equilibrium method; M.L.M. = Maximum Likelihood Method; M.M. = Median Method; E.R.M. = Empirical Regression Method by Siegloch [51]; L.M. = Logit Model; W.M. = Wu's Model; P.M. = Proposed Model by authors [53]; n.a. $=$ not available

the best results. Follow-up headways were measured; the median values of this headway was selected as a better measure than the mean. The minimum and maximum values of the (mean) critical headway were estimated both for single-lane roundabouts (see Table 1), and for double-lane roundabouts (see Table 2), as well as for turbo roundabouts (see Table 3); the same tables show the values of the follow-up headway. It should be noted that for double-lane roundabouts the mean values of critical and follow-up headways were differentiated by each entry lane (i.e. for the left- and right-lane at entries, where data were available) and distinguished for the innerand outer circulating lanes. Moreover, a further distinction was made between the major road and the minor road at turbo-roundabouts to consider two antagonist traffic streams for the left entry lane of minor roads, and only an antagonist traffic stream for the left- and the right-lane of major roads and for the right entry lane of minor roads. The same tables also show the corresponding values of the standard deviation.

\subsubsection{Italian studies}

The Italian experience on measurement of critical and follow-up headways includes investigations recently conducted by Gazzarri et al. [45] at single-lane and multilane roundabouts. Various well-known techniques for measuring the critical headway using field data were applied, i.e. maximum likelihood method [19], median method [46] and Raff's method [47]; however, the values of the critical headways obtained by the maximum likelihood method represented the best result and they were used in the following statistical analysis (see next section 3). Gazzarri et al. [45] assumed the log-normal distribution for the probabilistic distribution of critical headways and obtained the mean and the variance of the log-normal function by maximizing the likelihood function. The likelihood function was defined as the probability that the critical headway distribution lies between the observed distribution of the largest rejected headways and the accepted headways. Once obtaining the individual follow-up headway, the mean follow-up headway and the standard deviation were calculated from recorded time events at sites under examination. The range of variability of the (mean) critical and the follow-up headways, identified by the minimum and maximum values of these parameters, as well as the corresponding values of the standard deviation, are reported in Tables 1 and 2.

Some further indications on the estimations of critical headways were derived from Romano [48] at three multilane roundabouts. For one site, the empirical distribution of critical headways showed two peaks, that characterized two classes of users and a double normal aleatory variable was chosen to fit the empirical distribution. For the other roundabouts the situation resulted more homogeneous and the gamma function was selected to interpret the empirical distributions. Nicolosi et al. [49] investigated three roundabouts: one single-lane roundabouts and two multi-lane roundabouts and measured the values of critical and follow-up headways; the 
Table 2 Critical and follow-up headways values for double-lane roundabouts

\begin{tabular}{|c|c|c|c|c|c|c|c|c|c|c|c|}
\hline \multirow[t]{3}{*}{ study name } & \multirow[t]{3}{*}{ country } & \multirow[t]{3}{*}{ estimation method applied } & \multirow[t]{3}{*}{ entry lane } & \multicolumn{4}{|c|}{ critical headway } & \multicolumn{4}{|c|}{ follow-up headway } \\
\hline & & & & \multicolumn{2}{|c|}{ mean $[\mathrm{s}]$} & \multicolumn{2}{|c|}{ st. deviation [s] } & \multicolumn{2}{|c|}{ mean $[\mathrm{s}]$} & \multicolumn{2}{|c|}{ st. deviation $[\mathrm{s}$} \\
\hline & & & & $\min$ & $\max$ & $\min$ & $\max$ & $\min$ & $\max$ & $\min$ & $\max$ \\
\hline Dahl \& Lee [75] & Canada & R.M., P.E. & & 3.50 & 6.10 & - & - & 1.60 & 5.00 & - & - \\
\hline De Luca et al. [52] & Italy & n.a. & & 3.22 & - & 0.80 & - & - & - & - & - \\
\hline Fortuijn [44] & The Netherlands & n.a. & left & 2.89 & 3.16 & 0.04 & 1.32 & 2.24 & 2.26 & - & - \\
\hline \multirow[t]{2}{*}{ Gazzarri et al. [45] } & Italy & M.L.M. & left & 3.59 & 4.42 & 0.64 & 1.14 & 2.16 & 3.10 & 0.49 & 0.95 \\
\hline & & & right & 3.19 & 4.33 & 0.61 & 1.08 & 2.44 & 2.91 & 0.58 & 0.76 \\
\hline \multirow[t]{2}{*}{ Greibe \& La Cour Lund [43] } & Denmark & K.M. & left & 3.90 & 4.10 & - & - & 2.60 & - & - & - \\
\hline & & & right & 3.90 & 4.20 & - & - & 2.70 & - & - & - \\
\hline Guo [77] & China & $\begin{array}{l}\text { R.M., M.L.M., } \\
\text { R.R.M., A.M. }\end{array}$ & & 2.62 & 3.20 & - & - & - & - & - & - \\
\hline \multirow[t]{2}{*}{ Hagring et al. [42] } & Denmark & M.L.M. & left & 4.36 & 4.68 & 1.10 & 1.82 & 2.79 & - & 0.87 & - \\
\hline & & & right & 3.68 & 4.49 & 1.20 & 1.68 & 2.89 & - & 1.03 & - \\
\hline Leemann \& Santel [40] & Switzerland & M.L.M. & & 3.22 & 4.33 & - & - & 2.27 & 2.63 & - & - \\
\hline Li et al. [71] & US & M.L.M. & left & 4.30 & - & 1.00 & - & 3.10 & - & 1.20 & - \\
\hline Manage et al. (2003) [79] & Japan & n.a. & & 3.26 & 4.90 & - & - & - & - & - & - \\
\hline Nicolosi et al. [49] & Italy & M.L.M., E.R.M. & & 1.87 & 2.94 & 0.35 & 1.01 & 1.87 & 2.50 & 0.42 & 0.55 \\
\hline \multirow[t]{2}{*}{ Qu Z et al. [76] } & China & M.L.M., R.M & left & 4.57 & 4.85 & - & - & - & - & - & - \\
\hline & & & right & 4.41 & 4.58 & - & - & - & - & - & - \\
\hline \multirow[t]{2}{*}{ Rodegerdts et al. [61] } & US & M.L.M. & left & 3.70 & 5.50 & 0.70 & 2.60 & 2.90 & 5.00 & 1.00 & 3.90 \\
\hline & & & right & 3.20 & 4.90 & 1.00 & 3.80 & 2.80 & 4.40 & 0.80 & 2.30 \\
\hline Romano [48] & Italy & n.a. & & 2.03 & 3.69 & 0.24 & 1.45 & - & - & - & - \\
\hline Vasconcelos et al. [55] & Portugal & $\begin{array}{l}\text { S.M., R.M., M.L.M., } \\
\text { W.M., L.M. }\end{array}$ & & 2.56 & 4.46 & - & - & 1.94 & 2.78 & - & - \\
\hline $\mathrm{Wu}$ [37] & Germany & n.a. & & 4.12 & - & - & - & - & 2.88 & - & - \\
\hline \multirow[t]{2}{*}{ Xu \& Tian [72] } & US & M.L.M. & left & 4.40 & 5.10 & 0.90 & 1.10 & 1.80 & 2.70 & 0.60 & 0.90 \\
\hline & & & right & 4.00 & 4.80 & 0.90 & 1.10 & 2.10 & 2.30 & 0.70 & 1.00 \\
\hline \multirow[t]{2}{*}{ Zheng et al. [17] } & US & M.L.M. & left & 3.30 & 4.80 & 0.60 & 1.40 & 2.10 & 3.10 & 0.70 & 1.40 \\
\hline & & & right & 3.00 & 4.40 & 0.60 & 1.50 & 2.20 & 3.00 & 0.50 & 1.20 \\
\hline
\end{tabular}

Note: R.M = Raff's method [47]; P.E. = Probability Equilibrium method; M.L.M. = Maximum Likelihood Method; M.M. = Median Method; S.M. = Siegloch's Method [51]; L.M. = Logit Model; W.M. = Wu's Model [37]; K.M.= ${ }_{K}$ rbes Model as referred by [43]; A.M. = Ashworth's method [78]; n.a. $=$ not available

method proposed by Dawson [50] and the regression method proposed by Siegloch [51] were applied. The analysis of experimental data showed that the hypothesis of Gamma distribution was always verified for the follow-up headway. De Luca et al. [52] investigated four existing rural roundabouts and used real data to calibrate a simulation model. The analysis of the sample allowed to identify the Gumbel distribution as the function that best approximated the observed distribution of the data. Table 2 reports the values of the estimated critical headway and the standard deviation.

\subsubsection{Portuguese studies}

In a Portuguese study a new critical-headway model to describe the gap-acceptance process at microscopic level for roundabouts was proposed [53]. Basing on a data sample collected at a one-lane urban roundabout in Coimbra, Portugal, the model was calibrated and then validated against conventional methods (i.e. such as Raff's method [47], Logit methods [54], maximum likelihood method [19]). The values of critical headways are shown in Table 1.

In another study Vasconcelos et al. [55] estimated critical headways and follow-up times basing on observations at six Portuguese roundabouts; gap-acceptance data were collected at each entry, for the left- and right-lanes independently. The Authors applied several estimation methods: Siegloch [51], Raff [47], Wu [38], maximum likelihood [19] and logit method [54]. The results revealed important specificities of the methods with significant effects on the capacity estimates. The comparison 
Table 3 Critical and follow-up headways values for turbo roundabouts

\begin{tabular}{|c|c|c|c|c|c|c|c|c|}
\hline \multirow[t]{3}{*}{ study name } & \multirow[t]{3}{*}{ country } & \multirow[t]{3}{*}{ entry } & \multirow[t]{3}{*}{ entry lane } & \multirow[t]{3}{*}{ circulating lane } & \multicolumn{4}{|c|}{ critical headway } \\
\hline & & & & & \multicolumn{2}{|c|}{ mean $[\mathrm{s}]$} & \multicolumn{2}{|c|}{ st. deviation [s] } \\
\hline & & & & & $\min$ & $\max$ & $\min$ & $\max$ \\
\hline Brilon et al. [39] & Germany & major & left & & 4.50 & - & - & - \\
\hline Fortuijn [44] & The Netherlands & major & left & & 3.37 & 3.72 & 0.36 & 0.95 \\
\hline Brilon et al. [39] & Germany & major & right & & 4.50 & - & - & - \\
\hline Fortuijn [44] & The Netherlands & major & right & & 3.67 & 4.17 & 0.85 & 1.59 \\
\hline \multirow[t]{2}{*}{ Brilon et al. [39] } & Germany & minor & left & inner & 4.00 & - & - & - \\
\hline & & minor & left & outer & 4.50 & - & - & - \\
\hline \multirow[t]{2}{*}{ Fortuijn [44] } & The Netherlands & minor & left & inner & 3.15 & 3.24 & 0.27 & 0.47 \\
\hline & & minor & left & outer & 2.79 & 3.42 & 0.50 & 0.80 \\
\hline Brilon et al. [39] & Germany & minor & right & outer & 4.50 & - & - & - \\
\hline Fortuijn [44] & The Netherlands & minor & right & outer & 3.37 & 4.93 & 0.51 & 2.28 \\
\hline
\end{tabular}

of the estimates with values from several countries indicated significant differences among them and suggested the presence of relevant driving style differences; as a consequence, Vasconcelos et al. [55] came to the conclusion that locally calibrated, country-specific, parameters should be preferred for capacity calculations.

\subsection{Non European studies}

\subsubsection{Australian Research}

Various researches and studies were developed in Australia focusing on geometric design, capacity and delays at roundabouts (see e.g. [25, 56-58]). Troutbeck [59] addressed the problem about suitability of the gap acceptance theory to adequately predict the capacity of a roundabout and developed an analytical equation based on gap acceptance characteristics which were measured at roundabouts operating below capacity. Critical and follow-up headways were related to roundabout geometry and capacity. Based on Troutbeck's studies for the Australian Road Research Board, some changes to the analysis and design of roundabouts were proposed [56, 60]. Troutbeck's critical headway research [56-60] led to the development of a lane-based model that considers the conflicting lane gaps as the combination of gaps between the vehicles of the circulating streams; thus, for the right entry lane, all conflicting vehicles have an influence on the entering drivers' behavior, which will be true in some cases and generally conservative. If a vehicle in the right entry lane enters at the same time as a vehicle is circulating in the inner conflicting lane, the defined accepted gap may be quite small [61].

Further detailed capacity expressions have been published in Australia; these are most recently available in Akçelik [62, 63] and have been incorporated into the software aaSIDRA
$[25,64]$. The roundabout capacity is calculated lane-by-lane. An important feature of this method is to treat the lanes at multi-lane entries as dominant and subdominant lanes to which different values of critical and follow-up headways are assigned; the lane with the largest flow rate is called dominant lane and other lanes are called subdominant lanes. The critical and follow-up headways for roundabouts were those predicted by Troutbeck [65]; however, the values adopted in Austroads [66] were modified. In order to prevent the prediction of very low follow-up headways, the maximum value of the inscribed diameter, used in the formula for calculating the follow-up headway in the case of the dominant lane, was limited to $80 \mathrm{~m}$. Furthermore, a maximum follow-up headway of $4 \mathrm{~s}$ (applied to dominant lanes only) and a maximum critical headway of $10 \mathrm{~s}$ (applied to all lanes) were used; in order to prevent the prediction of very large values of follow-up and critical headways, the inscribed diameter value was limited to $20 \mathrm{~m} \mathrm{[66].} \mathrm{The} \mathrm{minimum} \mathrm{and} \mathrm{maximum} \mathrm{values} \mathrm{of} \mathrm{the} \mathrm{follow-}$ up headway in use into the recent versions of the software aaSIDRA are $1.2 \mathrm{~s}$ and $4 \mathrm{~s}$ (applied to all lanes), respectively; in turn, the minimum and maximum values of the critical headway are 2.2 and $8 \mathrm{~s}$, respectively. Currently aaSIDRA Intersection offers two roundabout capacity model options: the US HCM 2010 model (see next sub-section) and the aaSIDRA standard roundabout capacity model; there are various key parameters involved in changing between the two models [67]. The reader is referred to the user guide for any detailed information.

Further investigation on five multi-lane roundabouts allowed to measure critical and follow-up headways [68]. The critical headway resulted equal to $3.2 \mathrm{~s}$ (ranging from $2.13 \mathrm{~s}$ to $4.31 \mathrm{~s}$ ), whereas the follow-up headway resulted equal to $2.3 \mathrm{~s}$ (with a minimum value of $1.44 \mathrm{~s}$ and a maximum value of $3.25 \mathrm{~s}$ ). 
Qu et al. [69] estimated the follow-up headways at a single lane roundabout in Australia during different periods. The mean value of the follow-up headway was found equal to $2.76 \mathrm{~s}$ with the standard deviation equal to $0.62 \mathrm{~s}$. In order to obtain the best estimate of the distribution of the follow-up headway, seven continuous distributions were used: inverse Gaussian, exponential, Normal, Lognormal, Gamma, Weibull, Erlang and Kolmongorov-Smirnov test. According to this study the inverse Gaussian distribution gave the best fit. Critical headways were also predicted (see Table 2).

\subsubsection{US Research}

The experience in design practice of modern roundabouts in the United States can be found in the successive editions of Roundabouts: informational guide $[2,5]$ which provide the most effective approach to the solution of many problems regarding planning, designing, and operational analysis for this kind of intersections. The FHWA Roundabout Guide [5] presents three capacity formulas for estimating the performance of roundabouts. These were intended for use as provisional formulas until further research could be conducted with US data. The FHWA method for urban compact roundabouts is based on German research [9,34, 41], whereas the method for single-lane is based on the UK's Kimber equations [11] with default values for each of the geometric parameters. The FHWA method for double-lane roundabouts is also based on the Kimber equations [11] with default values for each of the geometric parameters. The NCHRP Report 572 [61] describes some investigations undertaken at a representative sample of single-lane and multi-lane roundabouts for the estimation of the critical headways. Based on a driver's critical headway being larger than the largest rejected headway and smaller than the accepted headway, calculation of critical headways was made using the maximum likelihood method [19]; the log-normal distribution was assumed as the probabilistic distribution of the critical headways. Critical headway estimates at single-lane sites were performed using three different ways of determining the critical headway: i) inclusion of all observations of gap acceptance, including accepted lags s; ii) inclusion of only observations that contain a rejected gap; iii) inclusion of only observations where queuing was observed during the entire minute the driver rejected a gap. The critical headway determined using method 1 resulted ranging between $3.9 \mathrm{~s}$ and $5.1 \mathrm{~s}$, with a weighted mean of $4.5 \mathrm{~s}$ and the mean standard deviation of $1.0 \mathrm{~s}$, whereas the critical headway determined using method 2 varied between $4.2 \mathrm{~s}$ and $5.9 \mathrm{~s}$, with a weighted mean of $5.0 \mathrm{~s}$ and the mean standard deviation of $1.2 \mathrm{~s}$; the critical headway determined using method 3 varied between $4.9 \mathrm{~s}$ and $5.6 \mathrm{~s}$, with a weighted average of $5.1 \mathrm{~s}$ and the mean standard deviation of $1.3 \mathrm{~s}$. Critical headway estimates at multi-lane sites were done using two different techniques [61]. The first technique assumed each entering lane and conflicting lane separately; vehicles entering from the right entry lane use the gaps in the outer circulating lane (and yield only to conflicting vehicles in the outer lane), whereas vehicles entering from the left entry lane use the combined gaps of the inner and outer circulating lanes. The second alternative technique allowed to estimate the critical headway for the entire approach, combining the entering lanes and conflicting lanes into single entering and conflicting streams, respectively. Lots of investigations have also been made for the purpose of calibrating the existing capacity models for roundabouts [61]; thus the critical headway was calculated with the original techniques used to develop those models. The critical headways for the multilane-site data were determined using observations conforming to methods 2 and 3 as described above for single-lane critical headway. The critical headways determined using method 2 varied between 3.4 $\mathrm{s}$ and $4.9 \mathrm{~s}$ in the right lane and $4.2 \mathrm{~s}$ and $5.5 \mathrm{~s}$ in the left lane (with a weighted mean of $4.3 \mathrm{~s}$ and $4.8 \mathrm{~s}$, respectively), whereas the critical headways determined using method 3 varied between $3.2 \mathrm{~s}$ and $4.9 \mathrm{~s}$ in the right lane and $3.7 \mathrm{~s}$ and $5.5 \mathrm{~s}$ in the left lane (with a weighted mean of $4.2 \mathrm{~s}$ and $4.6 \mathrm{~s}$, respectively). It is noteworthy that some sites have less than 50 critical headway observations for individual lanes; thus, while the average critical headway of each site could change with a larger sample size, the result was indicative of the average behavior of the site during those minutes when queuing was observed.

Based on a recent analysis of lane-based US field data, HCM [21] proposes a capacity model for single-lane and multi-lane roundabout entries which can be viewed both as an exponential regression model and a gap-acceptance model [67]. The HCM multi-lane capacity model was also developed for the right-lane and the left-lane of a two-lane entry; the behavioral parameters are then related to each specific entry lane [21]. The mean critical and the follow-up headways, as derived from the capacity formula for single-lane roundabouts, are equal to $5.19 \mathrm{~s}$ and $3.19 \mathrm{~s}$, respectively. In turn, the mean critical and the follow-up headways for right lane, as derived from the capacity formula for double-lane roundabouts, are equal to $4.11 \mathrm{~s}$ and $3.19 \mathrm{~s}$ respectively, whereas the mean critical and the follow-up headways for left lane are equal to $4.29 \mathrm{~s}$ and $3.19 \mathrm{~s}$, respectively [21].

With regard to the follow-up headway estimations at single-lane roundabouts, calculation was made basing on a value of the move-up time - the time the next vehicle takes to move into entry position - less than $6 \mathrm{~s}$; this value indicates a queued condition. The minimum and maximum values of the mean follow-up headways for the right and the left entry lanes with their standard deviation values are reported in Tables 1 and 2. The HCM 2010 roundabout capacity model [21] is based on research on US roundabouts [61], and is fully integrated into SIDRA intersection software [68]. 
The values of critical and the follow-up headways above are different from values proposed by the HCM 2000 [14]. Based on background provided by Troutbeck [70], the HCM 2000 [14] introduced the method only for single-lane roundabouts [14]; thus an upper and a lower bound of $4.1 \mathrm{~s}$ and $4.6 \mathrm{~s}$ were proposed for the critical headway, whereas an upper and lower bounds of $2.6 \mathrm{~s}$ and $3.1 \mathrm{~s}$, respectively, were introduced for the follow-up headway.

Further investigations for the estimation of the critical and follow-up headways were conducted by Zheng et al. [17]. Critical and follow-up headway data were extracted for four roundabouts. The estimation of the critical headways included the mean and the standard deviation, following the current state-of-practice maximum likelihood method [19]; estimation of the follow-up headways included the sample average and standard deviation. Other factors as the consideration of the adjacent exiting vehicles, vehicle type and queue lengths were also investigated. The assumption of log-normal distribution for the critical headway was made as suggested by Troutbeck [24] and used in NCHRP Report 572 [61]. Critical and follow-up headways were estimated considering (or not considering) exiting vehicles. For multi-lane roundabouts, engineering judgment was required to examine the different scheme of conflicts with one or two antagonist traffic streams faced by right- or left-turning vehicles from entries. The minimum and maximum values of the mean critical and follow-up headways at single- and multi-lane roundabouts with their standard deviations are reported in Tables 1 and 2 .

Li et al. [71] also estimated the critical headway through the maximum likelihood method [19]; the assumption of lognormal distribution for the critical headway was made. However, they refer only the mean values of the critical and follow-up headways (with the corresponding values of deviation standard) for the most congested entry lane (i.e. the left entry lane) of the double-lane roundabout which was examined (see Table 2).

$\mathrm{Xu}$ and Tian [72] collected headway and gapacceptance characteristics, measurement of geometry and vehicle speeds at Californian roundabouts. Critical headways were obtained for single-lane and multi-lane roundabout sites; the maximum likelihood methodology was used to estimate these headways [41]. At single-lane

Table 4 Summary results for critical headways at single-lane roundabouts

\begin{tabular}{|c|c|c|c|c|c|c|c|c|}
\hline study name & subgroup within study & mean $[\mathrm{s}]$ & sample size & st error $[\mathrm{s}]$ & $Z$ - value & $\mathrm{p}$ - value & Q & $\mathrm{I}^{2}[\%]$ \\
\hline Gazzarri et al. [45] & $\mathrm{A}_{1}$ & 3.80 & 71 & 0.11 & 35.98 & 0.00 & 23.28 & 1.19 \\
\hline Gazzarri et al. [45] & $\mathrm{A}_{2}$ & 3.99 & 98 & 0.08 & 50.00 & 0.00 & 23.28 & 1.19 \\
\hline Gazzarri et al. [45] & $\mathrm{A}_{3}$ & 4.10 & 47 & 0.14 & 29.59 & 0.00 & 23.28 & 1.19 \\
\hline Gazzarri et al. [45] & $\mathrm{A}_{4}$ & 3.54 & 61 & 0.09 & 41.27 & 0.00 & 23.28 & 1.19 \\
\hline Rodegerdts et al. [61] & $\mathrm{B}_{1}$ & 4.20 & 733 & 0.04 & 113.71 & 0.00 & 23.28 & 1.19 \\
\hline Rodegerdts et al. [61] & $\mathrm{B}_{2}$ & 4.90 & 76 & 0.15 & 32.08 & 0.00 & 23.28 & 1.19 \\
\hline Rodegerdts et al. [61] & $\mathrm{B}_{3}$ & 4.30 & 1062 & 0.05 & 107.47 & 0.00 & 23.28 & 1.19 \\
\hline Rodegerdts et al. [61] & $\mathrm{B}_{4}$ & 4.20 & 820 & 0.02 & 272.12 & 0.00 & 23.28 & 1.19 \\
\hline Rodegerdts et al. [61] & $\mathrm{B}_{5}$ & 5.10 & 98 & 0.05 & 85.04 & 0.00 & 23.28 & 1.19 \\
\hline Rodegerdts et al. [61] & $\mathrm{B}_{6}$ & 4.20 & 557 & 0.04 & 94.21 & 0.00 & 23.28 & 1.19 \\
\hline Rodegerdts et al. [61] & $\mathrm{B}_{7}$ & 4.60 & 92 & 0.10 & 47.46 & 0.00 & 23.28 & 1.19 \\
\hline Rodegerdts et al. [61] & $\mathrm{B}_{8}$ & 4.40 & 237 & 0.03 & 140.13 & 0.00 & 23.28 & 1.19 \\
\hline Rodegerdts et al. [61] & $\mathrm{B}_{9}$ & 4.20 & 1314 & 0.03 & 133.63 & 0.00 & 23.28 & 1.19 \\
\hline Rodegerdts et al. [61] & $\mathrm{B}_{10}$ & 4.80 & 197 & 0.10 & 50.49 & 0.00 & 23.28 & 1.19 \\
\hline Rodegerdts et al. [61] & $\mathrm{B}_{11}$ & 4.90 & 481 & 0.05 & 90.11 & 0.00 & 23.28 & 1.19 \\
\hline Rodegerdts et al. [61] & $\mathrm{B}_{12}$ & 4.30 & 3244 & 0.07 & 63.03 & 0.00 & 23.28 & 1.19 \\
\hline Rodegerdts et al. [61] & $\mathrm{B}_{13}$ & 3.90 & 233 & 0.12 & 37.63 & 0.00 & 23.28 & 1.19 \\
\hline Rodegerdts et al. [61] & $\mathrm{B}_{14}$ & 4.10 & 528 & 0.03 & 138.41 & 0.00 & 23.28 & 1.19 \\
\hline Zheng et al. [17] & $\mathrm{C}_{1}$ & 5.50 & 548 & 0.09 & 64.38 & 0.00 & 23.28 & 1.19 \\
\hline Zheng et al. [17] & $\mathrm{C}_{2}$ & 4.60 & 588 & 0.05 & 92.95 & 0.00 & 23.28 & 1.19 \\
\hline Zheng et al. [17] & $\mathrm{C}_{3}$ & 4.80 & 282 & 0.08 & 57.58 & 0.00 & 23.28 & 1.19 \\
\hline Zheng et al. [17] & $\mathrm{C}_{4}$ & 3.80 & 318 & 0.06 & 67.76 & 0.00 & 23.28 & 1.19 \\
\hline Fortuijn [44] & $\mathrm{D}_{1}$ & 3.16 & 101 & 0.03 & 113.42 & 0.00 & 23.28 & 1.19 \\
\hline Fortuijn [44] & $\mathrm{D}_{2}$ & 3.28 & 108 & 0.02 & 179.40 & 0,00 & 23.28 & 1.19 \\
\hline summary effect (random) & & 4.27 & & 0.11 & 37.46 & 0.00 & 23.28 & 1.19 \\
\hline
\end{tabular}


roundabouts the critical headway resulted ranging between $4.5 \mathrm{~s}$ and $5.3 \mathrm{~s}$, with a mean value of $4.8 \mathrm{~s}$, whereas at double-lane roundabouts the critical headway for the left lane varies between $4.4 \mathrm{~s}$ and $5.1 \mathrm{~s}$ with a mean value of $4.7 \mathrm{~s}$, and the critical headway for the right lane varied between $4.0 \mathrm{~s}$ and $4.8 \mathrm{~s}$, with a mean value of $4.4 \mathrm{~s}$. Unlike for critical headway estimation, follow-up headways were obtained directly from recorded time events; the minimum and maximum values of the critical and follow-up headways estimated for the examined sites are shown in Tables 1 and 2. Further field observations were made by Abrams et al. [73]. The Raff's method [47] was used to calculate the critical headway. For the single-lane roundabout a value $2.2 \mathrm{~s}$ was found for the critical headway.

Mensah et al. [74] measured the behavioral parameters at two roundabouts in Maryland, US; they collected the accepted and rejected gaps and the follow-up headways. These headways were compared with those obtained in the same sites four year before and the critical headway values resulted reduced, probably due to experience gained by users in the meantime with this type of intersections. The mean values of critical headways were recorded equal to $2.50 \mathrm{~s}$ and $2.60 \mathrm{~s}$ for the two sites examined, against values of $3.91 \mathrm{~s}$ and $3.85 \mathrm{~s}$ obtained in 2005.

\subsubsection{Canadian Studies}

Dahl and Lee [75] observed vehicle movements at 11 roundabouts in Vermont, Wisconsin, and Ontario, Canada, and estimated gap-acceptance parameters for cars and heavy vehicles separately in order to examine the effect of heavy vehicles on the entry capacity of roundabouts. Two conventional methods were used to estimate the critical headway at all roundabouts. The mean critical headway resulted ranging

Table 5 Summary results for follow-up headways at single-lane roundabouts

\begin{tabular}{|c|c|c|c|c|c|c|c|c|}
\hline study name & subgroup within study & mean $[\mathrm{s}]$ & sample size & st error $[\mathrm{s}]$ & $\mathrm{Z}$ - value & $\mathrm{p}$ - value & Q & $\mathrm{I}^{2}[\%]$ \\
\hline Gazzarri et al. [45] & $\mathrm{A}_{1}$ & 2.59 & 500 & 0.04 & 64.35 & 0.00 & 33.90 & 20.40 \\
\hline Gazzarri et al. [45] & $\mathrm{A}_{2}$ & 2.65 & 155 & 0.06 & 47.81 & 0.00 & 33.90 & 20.40 \\
\hline Gazzarri et al. [45] & $\mathrm{A}_{3}$ & 2.76 & 190 & 0.05 & 55.95 & 0.00 & 33.90 & 20.40 \\
\hline Gazzarri et al. [45] & $\mathrm{A}_{4}$ & 2.52 & 226 & 0.05 & 47.35 & 0.00 & 33.90 & 20.40 \\
\hline Nicolosi et al. [49] & $\mathrm{B}_{1}$ & 3.15 & 386 & 0.03 & 104.89 & 0.00 & 33.90 & 20.40 \\
\hline Rodegerdts et al. [61] & $\mathrm{C}_{1}$ & 3.20 & 637 & 0.04 & 73.42 & 0.00 & 33.90 & 20.40 \\
\hline Rodegerdts et al. [61] & $\mathrm{C}_{2}$ & 3.80 & 28 & 0.11 & 35.55 & 0.00 & 33.90 & 20.40 \\
\hline Rodegerdts et al. [61] & $\mathrm{C}_{3}$ & 3.60 & 1225 & 0.04 & 82.32 & 0.00 & 33.90 & 20.40 \\
\hline Rodegerdts et al. [61] & $\mathrm{C}_{4}$ & 3.10 & 522 & 0.08 & 40.47 & 0.00 & 33.90 & 20.40 \\
\hline Rodegerdts et al. [61] & $\mathrm{C}_{5}$ & 3.20 & 39 & 0.03 & 127.39 & 0.00 & 33.90 & 20.40 \\
\hline Rodegerdts et al. [61] & $\mathrm{C}_{6}$ & 3.10 & 41 & 0.09 & 33.96 & 0.00 & 33.90 & 20.40 \\
\hline Rodegerdts et al. [61] & $\mathrm{C}_{7}$ & 3.10 & 262 & 0.05 & 65.98 & 0.00 & 33.90 & 20.40 \\
\hline Rodegerdts et al. [61] & $\mathrm{C}_{8}$ & 2.90 & 33 & 0.12 & 23.58 & 0.00 & 33.90 & 20.40 \\
\hline Rodegerdts et al. [61] & $\mathrm{C}_{9}$ & 2.90 & 86 & 0.06 & 52.73 & 0.00 & 33.90 & 20.40 \\
\hline Rodegerdts et al. [61] & $\mathrm{C}_{10}$ & 2.60 & 126 & 0.04 & 60.46 & 0.00 & 33.90 & 20.40 \\
\hline Rodegerdts et al. [61] & $\mathrm{C}_{11}$ & 3.50 & 753 & 0.25 & 14.25 & 0.00 & 33.90 & 20.40 \\
\hline Rodegerdts et al. [61] & $\mathrm{C}_{12}$ & 3.30 & 334 & 0.03 & 105.00 & 0.00 & 33.90 & 20.40 \\
\hline Rodegerdts et al. [61] & $\mathrm{C}_{13}$ & 3.40 & 2282 & 0.05 & 70.62 & 0.00 & 33.90 & 20.40 \\
\hline Rodegerdts et al. [61] & $\mathrm{C}_{14}$ & 4.30 & 120 & 0.24 & 17.90 & 0.00 & 33.90 & 20.40 \\
\hline Rodegerdts et al. [61] & $\mathrm{C}_{15}$ & 3.50 & 453 & 0.22 & 16.01 & 0.00 & 33.90 & 20.40 \\
\hline Rodegerdts et al. [61] & $\mathrm{C}_{16}$ & 3.10 & 80 & 0.06 & 50.18 & 0.00 & 33.90 & 20.40 \\
\hline Rodegerdts et al. [61] & $\mathrm{C}_{17}$ & 3.40 & 400 & 0.19 & 17.76 & 0.00 & 33.90 & 20.40 \\
\hline Rodegerdts et al. [61] & $\mathrm{C}_{18}$ & 3.30 & 438 & 0.12 & 27.82 & 0.00 & 33.90 & 20.40 \\
\hline Zheng et al. [17] & $\mathrm{D}_{1}$ & 2.60 & 1223 & 0.04 & 64.95 & 0.00 & 33.90 & 20.40 \\
\hline Zheng et al. [17] & $\mathrm{D}_{2}$ & 3.80 & 1198 & 0.08 & 50.59 & 0.00 & 33.90 & 20.40 \\
\hline Zheng et al. [17] & $\mathrm{D}_{3}$ & 2.30 & 828 & 0.03 & 66.18 & 0.00 & 33.90 & 20.40 \\
\hline Zheng et al. [17] & $\mathrm{D}_{4}$ & 3.10 & 768 & 0.08 & 39.05 & 0.00 & 33.90 & 20.40 \\
\hline Qu X et al. [69] & $\mathrm{E}_{1}$ & 2.76 & 171 & 0.05 & 58.21 & 0.00 & 33.90 & 20.40 \\
\hline summary effect (random) & & 3.10 & & 0.07 & 41.82 & 0.00 & 33.90 & 20.40 \\
\hline
\end{tabular}


between $3.9 \mathrm{~s}$ and $4.8 \mathrm{~s}$ for cars, whereas the critical headway resulted ranging between $4.5 \mathrm{~s}$ and $6.1 \mathrm{~s}$ for heavy vehicles. However, as expected, the critical headway for heavy vehicles was longer than that for cars since heavy vehicles require longer headway to enter the roundabout because of their larger size and slower acceleration. The follow-up headways for different vehicle-following conditions were also calculated [75]. The follow-up headway resulted longer when a heavy vehicle was a lead vehicle, a following vehicle, or both. The follow-up headway for the heavy vehicle-car case was longer than the follow-up headway for the car-heavy vehicle case, because it took a longer time for the lead heavy vehicle to enter the roundabout than for the lead car [75]; it was also found that the follow-up headway for the heavy vehicleheavy vehicle case was the longest because of the lead heavy vehicle's slow entry and the following heavy vehicle's low acceleration.

\subsubsection{Chinese studies}

In a Chinese study concerning capacity prediction models, the values of critical headways were obtained for a double-lane roundabouts [76]. The values of behavioral parameters both for the right and the left entry lane with two different methods were estimated. Thus, based on the field data, the maximum likelihood method [19] and the Raff's method [47] were applied. Assuming that critical headways followed the log-normal distribution, the mean value and the deviation standard of critical headway were obtained. The results of two methods were similar with a maximum difference of about $3.8 \%$.

Further investigations at an existing roundabout were carried out by Guo [77] which estimated the value of mean critical headway using different conventional methods (i.e. maximum likelihood method [19, 41], Raff's method [47], Ashworth's method [78]). The Ashworth's method gave the highest value, whereas maximum likelihood method provided the lowest value of critical headway. Despite its simplicity in calculating the critical headway the Ashworth's method [78] assumes the exponential distribution for the headway of circulating stream and the normal distribution for the accepted gaps; this situation is often difficult to satisfy on field because traffic streams can result influenced by upstream traffic conditions or low flow rates in undersaturated conditions.

\subsubsection{Japanese studies}

In a Japanese study critical and follows up headway measurements were made at a multi-lane roundabout [79]. In order to estimate the behavioral parameters, the accepted and rejected gaps in the circulating stream were collected. Based on these data the cumulative curves of the rejected and accepted gaps were built; mean critical headways were found ranging between $3.00 \mathrm{~s}$ and $3.80 \mathrm{~s}$ depending on the entry approach, while the mean follow-up headway ranged between $3.26 \mathrm{~s}$ and $4.90 \mathrm{~s}$.

Table 6 Summary results for critical headways at double-lane roundabouts - outer circulating lane

\begin{tabular}{|c|c|c|c|c|c|c|c|c|}
\hline study name & subgroup within study & mean $[\mathrm{s}]$ & sample size & st error $[\mathrm{s}]$ & $\mathrm{Z}$ - value & $\mathrm{p}$ - value & Q & $\mathrm{I}^{2}[\%]$ \\
\hline Gazzarri et al. [45] & $\mathrm{A}_{1}$ & 4.33 & 59 & 0.14 & 30.80 & 0.00 & 15.12 & 0.00 \\
\hline Gazzarri et al. [45] & $\mathrm{A}_{2}$ & 3.50 & 36 & 0.13 & 26.25 & 0.00 & 15.12 & 0.00 \\
\hline Gazzarri et al. [45] & $\mathrm{A}_{3}$ & 3.85 & 56 & 0.12 & 32.74 & 0.00 & 15.12 & 0.00 \\
\hline Gazzarri et al. [45] & $\mathrm{A}_{4}$ & 3.56 & 43 & 0.09 & 38.27 & 0.00 & 15.12 & 0.00 \\
\hline Gazzarri et al. [45] & $\mathrm{A}_{5}$ & 3.19 & 69 & 0.10 & 33.12 & 0.00 & 15.12 & 0.00 \\
\hline Rodegerdts et al. [61] & $\mathrm{B}_{1}$ & 4.90 & 307 & 0.12 & 40.88 & 0.00 & 15.12 & 0.00 \\
\hline Rodegerdts et al. [61] & $\mathrm{B}_{2}$ & 3.40 & 35 & 0.20 & 16.76 & 0.00 & 15.12 & 0.00 \\
\hline Rodegerdts et al. [61] & $\mathrm{B}_{3}$ & 4.10 & 813 & 0.06 & 73.06 & 0.00 & 15.12 & 0.00 \\
\hline Rodegerdts et al. [61] & $\mathrm{B}_{4}$ & 4.20 & 604 & 0.05 & 79.40 & 0.00 & 15.12 & 0.00 \\
\hline Rodegerdts et al. [61] & $\mathrm{B}_{5}$ & 4.00 & 115 & 0.11 & 35.75 & 0.00 & 15.12 & 0.00 \\
\hline Rodegerdts et al. [61] & $\mathrm{B}_{6}$ & 4.40 & 182 & 0.10 & 42.40 & 0.00 & 15.12 & 0.00 \\
\hline Zheng et al. [17] & $\mathrm{C}_{1}$ & 3.50 & 319 & 0.04 & 78.14 & 0.00 & 15.12 & 0.00 \\
\hline Zheng et al. [17] & $\mathrm{C}_{2}$ & 3.80 & 268 & 0.07 & 51.84 & 0.00 & 15.12 & 0.00 \\
\hline Zheng et al. [17] & $\mathrm{C}_{3}$ & 4.10 & 194 & 0.08 & 51.91 & 0.00 & 15.12 & 0.00 \\
\hline Zheng et al. [17] & $\mathrm{C}_{4}$ & 4.40 & 194 & 0.11 & 40.86 & 0.00 & 15.12 & 0.00 \\
\hline Zheng et al. [17] & $\mathrm{C}_{5}$ & 3.00 & 639 & 0.02 & 126.39 & 0.00 & 15.12 & 0.00 \\
\hline Zheng et al. [17] & $\mathrm{C}_{6}$ & 3.40 & 670 & 0.04 & 88.01 & 0.00 & 15.12 & 0.00 \\
\hline Fortuijn [44] & $\mathrm{D}_{1}$ & 2.89 & 11 & 0.40 & 7.26 & 0.00 & 15.12 & 0.00 \\
\hline summary effect (random) & & 3.82 & & 0.13 & 28.79 & 0.00 & 15.12 & 0.00 \\
\hline
\end{tabular}




\section{Statistical treatment of the systematic review on critical and follow-up headways}

The above systematic review was completed performing the statistical treatment of data of the individual studies with the objective to summarize the results and to calculate the summary effect; for this purpose a metaanalysis was implemented as part of the literature review [29]. Unlike the narrative review, where the reviewers implicitly assign some level of importance to each study, in meta-analysis the weights assigned to each study are based on objective criteria that will be specified in advance. According to the meta-analysis principles, the studies included in the analysis were selected through a set of rules. The inclusion criteria, used for the selection of the studies, were consistent with the following objectives: i) to handle the same geometric scheme of roundabouts (i.e. single-lane roundabouts, double-lane roundabouts or turbo-roundabouts); ii) to face with comparable estimation methods of headways and/or similar detection techniques; iii) to get the entire distribution of the headways (i.e. mean, variance and sample size).

Before introducing the calculations and the modelling results, a brief overview of the models on which the metaanalysis is based on will be described.

\subsection{Fixed-effect model Vs random-effects model}

The meta-analyses are based on one of two statistical models, the fixed-effect model or the random-effects model [29].

Under the fixed-effect model, all studies in the analysis share the same true effect size (namely the effect size in the population); all differences in observed effects are due to sampling error. Thus the summary effect is the estimate of this common effect size. On the contrary, under the randomeffects model, the true effect is different from study to study and the summary effect is the estimate of the mean of the distribution of effect sizes. Since in this case, studies can differ in the number of observations or some characteristics of the geometric design (e.g. the width of the roundabout ring or the entry lanes, population characteristics, etc.), there may be different effect sizes to the base of each study. It is noteworthy that if it is possible to consider an infinite number of studies, the true effect sizes for these studies would be distributed about the mean. The effect sizes in the studies that were carried out, indeed, are assumed to represent a random sample of these effect sizes; hence the term random effects is used since there is an array of true effects.

Furthermore, when setting weights to the different studies in the fixed-effect model, we can largely ignore the information in the smaller studies since we have better information about the same effect size in the larger studies. This

Table 7 Summary results for critical headways at double-lane roundabouts - inner circulating lane

\begin{tabular}{|c|c|c|c|c|c|c|c|c|}
\hline study name & subgroup within study & mean $[\mathrm{s}]$ & sample size & st error $[\mathrm{s}]$ & $\mathrm{Z}$ - value & $\mathrm{p}$ - value & Q & $\mathrm{I}^{2}[\%]$ \\
\hline Gazzarri et al. [45] & $\mathrm{A}_{1}$ & 4.05 & 62 & 0.10 & 39.37 & 0.00 & 16.78 & 0.00 \\
\hline Gazzarri et al. [45] & $\mathrm{A}_{2}$ & 3.59 & 53 & 0.09 & 40.84 & 0.00 & 16.78 & 0.00 \\
\hline Gazzarri et al. [45] & $\mathrm{A}_{3}$ & 4.42 & 51 & 0.16 & 27.69 & 0.00 & 16.78 & 0.00 \\
\hline Gazzarri et al. [45] & $\mathrm{A}_{4}$ & 3.71 & 54 & 0.10 & 36.35 & 0.00 & 16.78 & 0.00 \\
\hline Gazzarri et al. [45] & $\mathrm{A}_{5}$ & 3.71 & 82 & 0.11 & 33.93 & 0.00 & 16.78 & 0.00 \\
\hline Rodegerdts et al. [61] & $\mathrm{B}_{1}$ & 5.50 & 468 & 0.12 & 45.76 & 0.00 & 16.78 & 0.00 \\
\hline Rodegerdts et al. [61] & $\mathrm{B}_{2}$ & 4.20 & 275 & 0.14 & 30.28 & 0.00 & 16.78 & 0.00 \\
\hline Rodegerdts et al. [61] & $\mathrm{B}_{3}$ & 4.30 & 17 & 0.39 & 11.08 & 0.00 & 16.78 & 0.00 \\
\hline Rodegerdts et al. [61] & B4 & 4.20 & 99 & 0.22 & 19.00 & 0.00 & 16.78 & 0.00 \\
\hline Rodegerdts et al. [61] & $\mathrm{B}_{5}$ & 4.40 & 237 & 0.09 & 48.38 & 0.00 & 16.78 & 0.00 \\
\hline Rodegerdts et al. [61] & $\mathrm{B}_{6}$ & 4.30 & 100 & 0.09 & 47.78 & 0.00 & 16.78 & 0.00 \\
\hline Rodegerdts et al. [61] & $\mathrm{B}_{7}$ & 5.00 & 73 & 0.16 & 30.51 & 0.00 & 16.78 & 0.00 \\
\hline Zheng et al. [17] & $\mathrm{C}_{1}$ & 4.20 & 343 & 0.06 & 64.82 & 0.00 & 16.78 & 0.00 \\
\hline Zheng et al. [17] & $\mathrm{C}_{2}$ & 4.10 & 966 & 0.03 & 127.43 & 0.00 & 16.78 & 0.00 \\
\hline Zheng et al. [17] & $\mathrm{C}_{3}$ & 4.80 & 492 & 0.06 & 76.05 & 0.00 & 16.78 & 0.00 \\
\hline Zheng et al. [17] & $\mathrm{C}_{4}$ & 3.70 & 414 & 0.03 & 107.55 & 0.00 & 16.78 & 0.00 \\
\hline Zheng et al. [17] & $\mathrm{C}_{5}$ & 3.30 & 875 & 0.02 & 162.69 & 0.00 & 16.78 & 0.00 \\
\hline Zheng et al. [17] & $\mathrm{C}_{6}$ & 4.40 & 490 & 0.05 & 88.54 & 0.00 & 16.78 & 0.00 \\
\hline Li et al. [71] & $\mathrm{D}_{1}$ & 4.30 & 648 & 0.04 & 109.46 & 0.00 & 16.78 & 0.00 \\
\hline Fortuijn [44] & $\mathrm{E}_{1}$ & 3.16 & 12 & 0.01 & 273.66 & 0.00 & 16.78 & 0.00 \\
\hline summary effect (random) & & 4.16 & & 0.13 & 31.24 & 0.00 & 16.78 & 0.00 \\
\hline
\end{tabular}


consideration does not apply to random model because in this case, the objective is to estimate the average effect for the studies considered; since each study provides information about a different effect size, the overall estimate cannot be influenced by a particular study. According to this logic, in a random model, it is not possible to give more weight to a study rather than another. So, in the fixed-effect model the only source of uncertainty is within the studies, whereas under the random-effects model there is the same source of uncertainty plus an additional source (i.e. between-studies variance) [29]. It follows that the variance, standard error, and confidence interval for the summary effect will always be larger in the randomeffects model than in the fixed-effect model. In general, the fixed-effect model is properly used when two conditions are met: i) all studies included in the analysis are functionally identical; ii) the scope is to compute the common effect size for the identified population, and not to generalize to other populations.

By contrast, under the random-effects model we allow that the true effect could vary from study to study [29]. Considering that the critical and follow-up headways are country/region-related, and then they can depend on traffic regulation, traffic behaviour, age and mentality of drivers population, types of vehicles, tradition of using roundabouts, etc., the effect size might be higher (or lower) in studies where the participants are older, or more educated, or healthier than in others, or when a variant of an installation (in our investigation the roundabout) is used more intensively, and so on. Because studies can differ in the mixes of participants and in the implementations of interventions, among other reasons, there may be different effect sizes underlying different studies.

Because in the case under examination data were collected from a series of studies conducted by several researchers operating independently, the choice to use the random-effects model was more justified than the fixed-effect model, as further specified in the next two sections.

\subsection{The Random-effects model}

The random-effect model, discussed above, starts with the assumption that the true effect size is not the same in all studies [29]. Indeed the effect size might differ from study to study as a consequence of the different sample size, geometric features of the roundabout, the context of insertion, the driver population characteristics, and so on. In order to estimate the mean of the distribution (the summary mean or the summary effect), we need to take account of two sources of variance: the original variance within-study and the variance between-studies.

For the purpose to obtain the most precise estimate of the overall mean, we compute a weighted mean, where the weight assigned to each study is the inverse of that study's variance [29]:

$$
W_{i}^{*}=\frac{1}{V_{Y i}^{*}}
$$

where $V_{Y i}^{*}=V_{Y i}+T^{2}$, in which $V_{Y i}$ is the variance withinstudy for study $i$ and $T^{2}$ is the variance between-studies. The

Table 8 Summary results for follow - up headways at double-lane roundabouts - right entry lane

\begin{tabular}{|c|c|c|c|c|c|c|c|c|}
\hline study name & subgroup within study & mean $[\mathrm{s}]$ & sample size & st error $[\mathrm{s}]$ & $Z$ - value & $\mathrm{p}$ - value & Q & $\mathrm{I}^{2}[\%]$ \\
\hline Gazzarri et al. [45] & $\mathrm{A}_{1}$ & 2.70 & 205 & 0.05 & 54.45 & 0.00 & 17.77 & 9.98 \\
\hline Gazzarri et al. [45] & $\mathrm{A}_{2}$ & 2.44 & 29 & 0.11 & 22.65 & 0.00 & 17.77 & 9.98 \\
\hline Gazzarri et al. [45] & $\mathrm{A}_{3}$ & 2.91 & 143 & 0.06 & 45.79 & 0.00 & 17.77 & 9.98 \\
\hline Gazzarri et al. [45] & $\mathrm{A}_{4}$ & 2.58 & 87 & 0.07 & 39.45 & 0.00 & 17.77 & 9.98 \\
\hline Gazzarri et al. [45] & $\mathrm{A}_{5}$ & 2.59 & 92 & 0.07 & 36.00 & 0.00 & 17.77 & 9.98 \\
\hline Rodegerdts et al. [61] & $\mathrm{B}_{1}$ & 3.10 & 648 & 0.06 & 52.61 & 0.00 & 17.77 & 9.98 \\
\hline Rodegerdts et al. [61] & $\mathrm{B}_{2}$ & 4.40 & 2 & 1.63 & 2.71 & 0.00 & 17.77 & 9.98 \\
\hline Rodegerdts et al. [61] & $\mathrm{B}_{3}$ & 3.10 & 104 & 0.11 & 28.74 & 0.00 & 17.77 & 9.98 \\
\hline Rodegerdts et al. [61] & B4 & 2.80 & 478 & 0.04 & 76.52 & 0.00 & 17.77 & 9.98 \\
\hline Rodegerdts et al. [61] & $\mathrm{B}_{5}$ & 3.10 & 1340 & 0.03 & 94.57 & 0.00 & 17.77 & 9.98 \\
\hline Rodegerdts et al. [61] & $\mathrm{B}_{6}$ & 3.00 & 1773 & 0.03 & 114.84 & 0.00 & 17.77 & 9.98 \\
\hline Zheng et al. [17] & $\mathrm{C}_{1}$ & 3.00 & 425 & 0.06 & 51.54 & 0.00 & 17.77 & 9.98 \\
\hline Zheng et al. [17] & $\mathrm{C}_{2}$ & 2.80 & 2206 & 0.02 & 119.56 & 0.00 & 17.77 & 9.98 \\
\hline Zheng et al. [17] & $\mathrm{C}_{3}$ & 2.20 & 22 & 0.11 & 20.64 & 0.00 & 17.77 & 9.98 \\
\hline Zheng et al. [17] & $\mathrm{C}_{4}$ & 2.60 & 128 & 0.11 & 24.51 & 0.00 & 17.77 & 9.98 \\
\hline Zheng et al. [17] & $\mathrm{C}_{5}$ & 2.20 & 600 & 0.03 & 67.36 & 0.00 & 17.77 & 9.98 \\
\hline Zheng et al. [17] & $\mathrm{C}_{6}$ & 2.02 & 17 & 0.12 & 18.14 & 0.00 & 17.77 & 9.98 \\
\hline summary effect (random) & & 2.72 & & 0.08 & 35.74 & 0.00 & 17.77 & 9.98 \\
\hline
\end{tabular}


Table 9 Summary results for follow - up headways at double-lane roundabouts - left entry lane

\begin{tabular}{|c|c|c|c|c|c|c|c|c|}
\hline study name & subgroup within study & mean $[\mathrm{s}]$ & sample size & st error $[\mathrm{s}]$ & $\mathrm{Z}$ - value & $\mathrm{p}$ - value & Q & $\mathrm{I}^{2}[\%]$ \\
\hline Gazzarri et al. [45] & $\mathrm{A}_{1}$ & 3.10 & 145 & 0.08 & 39.29 & 0.00 & 22.32 & 19.36 \\
\hline Gazzarri et al. [45] & $\mathrm{A}_{2}$ & 2.16 & 57 & 0.06 & 33.28 & 0.00 & 22.32 & 19.36 \\
\hline Gazzarri et al. [45] & $\mathrm{A}_{3}$ & 2.77 & 59 & 0.09 & 29.55 & 0.00 & 22.32 & 19.36 \\
\hline Gazzarri et al. [45] & $\mathrm{A}_{4}$ & 2.66 & 82 & 0.07 & 39.49 & 0.00 & 22.32 & 19.36 \\
\hline Gazzarri et al. [45] & $\mathrm{A}_{5}$ & 2.56 & 124 & 0.06 & 43.19 & 0.00 & 22.32 & 19.36 \\
\hline Rodegerdts et al. [61] & $\mathrm{B}_{1}$ & 3.10 & 1792 & 0.03 & 119.30 & 0.00 & 22.32 & 19.36 \\
\hline Rodegerdts et al. [61] & $\mathrm{B}_{2}$ & 3.30 & 315 & 0.07 & 48.81 & 0.00 & 22.32 & 19.36 \\
\hline Rodegerdts et al. [61] & $\mathrm{B}_{3}$ & 4.70 & 6 & 0.98 & 4.80 & 0.00 & 22.32 & 19.36 \\
\hline Rodegerdts et al. [61] & $\mathrm{B}_{4}$ & 3.20 & 73 & 0.13 & 24.86 & 0.00 & 22.32 & 19.36 \\
\hline Rodegerdts et al. [61] & $\mathrm{B}_{5}$ & 3.40 & 85 & 0.13 & 26.12 & 0.00 & 22.32 & 19.36 \\
\hline Rodegerdts et al. [61] & $\mathrm{B}_{6}$ & 3.30 & 180 & 0.08 & 40.25 & 0.00 & 22.32 & 19.36 \\
\hline Rodegerdts et al. [61] & $\mathrm{B}_{7}$ & 3.50 & 28 & 0.28 & 12.35 & 0.00 & 22.32 & 19.36 \\
\hline Zheng et al. [17] & $\mathrm{C}_{1}$ & 3.10 & 698 & 0.05 & 63.00 & 0.00 & 22.32 & 19.36 \\
\hline Zheng et al. [17] & $\mathrm{C}_{2}$ & 2.80 & 1768 & 0.03 & 98.11 & 0.00 & 22.32 & 19.36 \\
\hline Zheng et al. [17] & $\mathrm{C}_{3}$ & 2.50 & 142 & 0.12 & 21.28 & 0.00 & 22.32 & 19.36 \\
\hline Zheng et al. [17] & $\mathrm{C}_{4}$ & 2.50 & 233 & 0.07 & 38.16 & 0.00 & 22.32 & 19.36 \\
\hline Zheng et al. [17] & $\mathrm{C}_{5}$ & 2.20 & 475 & 0.03 & 68.50 & 0.00 & 22.32 & 19.36 \\
\hline Zheng et al. [17] & $\mathrm{C}_{6}$ & 2.10 & 100 & 0.08 & 26.25 & 0.00 & 22.32 & 19.36 \\
\hline Li et al. [71] & $\mathrm{D}_{1}$ & 3.10 & 638 & 0.05 & 65.25 & 0.00 & 22.32 & 19.36 \\
\hline summary effect (random) & & 2.85 & & 0.10 & 29.58 & 0.00 & 22.32 & 19.36 \\
\hline
\end{tabular}

Table 10 Summary results for critical headways at turbo roundabout

\begin{tabular}{|c|c|c|c|c|c|c|c|c|c|}
\hline \multicolumn{2}{|l|}{ study name } & subgroup within study & mean $[\mathrm{s}]$ & sample size & st error [s] & $\mathrm{z}$ - value & $\mathrm{p}$ - value & Q & $\mathrm{I}^{2}[\%]$ \\
\hline \multicolumn{10}{|l|}{ major entry } \\
\hline \multirow[t]{5}{*}{ left entry lane } & Fortuijn [44] & $\mathrm{A}_{1}$ & 3.37 & 253 & 0.05 & 61.61 & 0.00 & 4.84 & 37.98 \\
\hline & Fortuijn [44] & $\mathrm{A}_{2}$ & 3.62 & 648 & 0.04 & 97.00 & 0.00 & 4.84 & 37.98 \\
\hline & Fortuijn [44] & $\mathrm{A}_{3}$ & 3.66 & 145 & 0.03 & 122.42 & 0.00 & 4.84 & 37.98 \\
\hline & Fortuijn [44] & $\mathrm{A}_{4}$ & 3.72 & 269 & 0.03 & 135.58 & 0.00 & 4.84 & 37.98 \\
\hline & summary effect (random) & & 3.60 & & 0.06 & 61.22 & 0.00 & 4.84 & 37.98 \\
\hline \multirow[t]{3}{*}{ right entry lane } & Fortuijn [44] & $\mathrm{A}_{1}$ & 3.67 & 421 & 0.04 & 88.59 & 0.00 & 1.00 & 0.00 \\
\hline & Fortuijn [44] & $\mathrm{A}_{2}$ & 4.17 & 273 & 0.10 & 43.33 & 0.00 & 1.00 & 0.00 \\
\hline & summary effect (random) & & 3.91 & & 0.25 & 15.66 & 0.00 & 1.00 & 0.00 \\
\hline \multicolumn{10}{|l|}{ minor entry } \\
\hline \multicolumn{10}{|l|}{ left entry lane } \\
\hline \multirow[t]{4}{*}{ outer circulating lane } & Fortuijn [44] & $\mathrm{A}_{1}$ & 2.79 & 83 & 0.05 & 50.84 & 0.00 & 2.91 & 31.22 \\
\hline & Fortuijn [44] & $\mathrm{A}_{2}$ & 3.07 & 154 & 0.06 & 54.43 & 0.00 & 2.91 & 31.22 \\
\hline & Fortuijn [44] & $\mathrm{A}_{3}$ & 3.42 & 35 & 0.14 & 25.29 & 0.00 & 2.91 & 31.22 \\
\hline & summary effect (random) & & 3.07 & & 0.15 & 20.85 & 0.00 & 2.91 & 31.22 \\
\hline \multirow[t]{4}{*}{ inner circulating lane } & Fortuijn [44] & $\mathrm{A}_{1}$ & 3.15 & 255 & 0.03 & 107.02 & 0.00 & 1.87 & 0.00 \\
\hline & Fortuijn [44] & $\mathrm{A}_{2}$ & 3.23 & 54 & 0.04 & 87.91 & 0.00 & 1.87 & 0.00 \\
\hline & Fortuijn [44] & $\mathrm{A}_{3}$ & 3.24 & 206 & 0.03 & 98.94 & 0.00 & 1.87 & 0.00 \\
\hline & summary effect (random) & & 3.20 & & 0.03 & 106.36 & 0.00 & 1.87 & 0.00 \\
\hline \multirow[t]{4}{*}{ right entry lane } & Fortuijn [44] & $\mathrm{A}_{1}$ & 3.37 & 69 & 0.06 & 54.89 & 0.00 & 10.66 & 81.23 \\
\hline & Fortuijn [44] & $\mathrm{A}_{2}$ & 3.48 & 434 & 0.04 & 99.31 & 0.00 & 10.66 & 81.23 \\
\hline & Fortuijn [44] & $\mathrm{A}_{3}$ & 4.93 & 118 & 0.21 & 23.49 & 0.00 & 10.66 & 81.23 \\
\hline & summary effect (random) & & 3.83 & & 0.20 & 18.70 & 0.00 & 10.66 & 81.23 \\
\hline
\end{tabular}


Table 11 Comparison between summary effect (random) and mean values for critical headways

\begin{tabular}{|c|c|c|c|c|c|}
\hline study name & roundabout & entry & entry lane & circulating lane & mean values $[\mathrm{s}]$ \\
\hline Gazzarri et al. [45] & single-lane & & & & 3.86 \\
\hline Rodegerdts et al. [61] & single-lane & & & & 4.30 \\
\hline Zheng et al. [17] & single-lane & & & & 4.77 \\
\hline Fortuijn [44] & single-lane & & & & 3.22 \\
\hline summary effect (random) & & & & & 4.27 \\
\hline Gazzarri et al. [45] & double-lane & & & outer & 3.69 \\
\hline Rodegerdts et al. [61] & double-lane & & & outer & 4.26 \\
\hline Zheng et al. [17] & double-lane & & & outer & 3.49 \\
\hline Fortuijn [44] & double-lane & & & outer & 2.89 \\
\hline summary effect (random) & & & & & 3.82 \\
\hline Gazzarri et al. [45] & double-lane & & & inner & 3.88 \\
\hline Rodegerdts et al. [61] & double-lane & & & inner & 4.77 \\
\hline Zheng et al. [17] & double-lane & & & inner & 4.01 \\
\hline Li et al. [71] & double-lane & & & inner & 4.30 \\
\hline Fortuijn [44] & double-lane & & & inner & 3.16 \\
\hline summary effect (random) & & & & & 4.16 \\
\hline Fortuijn [44] & turbo & major & left & & 3.60 \\
\hline summary effect (random) & & & & & 3.60 \\
\hline Fortuijn [44] & turbo & major & right & & 3.87 \\
\hline summary effect (random) & & & & & 3.91 \\
\hline Fortuijn [44] & turbo & minor & left & inner & 3.19 \\
\hline summary effect (random) & & & & & 3.20 \\
\hline Fortuijn [44] & turbo & minor & left & outer & 3.03 \\
\hline summary effect (random) & & & & & 3.07 \\
\hline Fortuijn [44] & turbo & minor & right & & 3.74 \\
\hline summary effect (random) & & & & & 3.83 \\
\hline
\end{tabular}

Table 12 Comparison between summary effect (random) and mean values for follow-up headways

\begin{tabular}{llll}
\hline study name & roundabout & entry lane & mean values [s] \\
\hline Gazzarri et al. [45] & single-lane & 2.61 \\
Nicolosi et al. [49] & single-lane & 3.15 \\
Rodegerdts et al. [61] & single-lane & 3.22 \\
Zheng et al. [17] & single-lane & 2.99 \\
Qu X et al. [69] & single-lane & & 2.76 \\
summary effect (random) & & & 3.10 \\
Gazzarri et al. [45] & double-lane & right & 2.70 \\
Rodegerdts L. et al. (2007) & double-lane & right & 3.03 \\
Zheng D. et al. (2011) & double-lane & right & 2.70 \\
summary effect (random) & & & 2.72 \\
Gazzarri et al. [45] & double-lane & left & 2.72 \\
Rodegerdts et al. [61] & double-lane & left & 3.16 \\
Zheng et al. [17] & double-lane & left & 2.72 \\
Li et al. [71] & & & 3.10 \\
summary effect (random) & & & 2.85 \\
\hline
\end{tabular}

weighted mean, $M^{*}$, is then computed with the following formula:

$M^{*}=\frac{\sum_{i=1}^{k} W_{i}^{*} Y_{i}}{\sum_{i=1}^{k} W_{i}^{*}}$

in which $Y_{i}$ is the mean for study $i$. The variance of the summary effect is estimated as the reciprocal of the sum of the weights:

$$
V_{M^{*}}=\frac{1}{\sum_{i=1}^{k} W_{i}^{*}}
$$

and the estimated standard error of the summary effect is then the square root of the variance as follows:

$S E_{M^{*}}=\sqrt{V_{M^{*}}}$ 
The $95 \%$ lower and upper limits for the summary effect are computed as follows:

$$
\begin{aligned}
& L L_{M^{*}}=M^{*}-1.96 S E_{M^{*}} \\
& U L_{M^{*}}=M^{*}+1.96 S E_{M^{*}}
\end{aligned}
$$

Finally, in a random model we must take into account the heterogeneity of studies. There are several measures of heterogeneity, one of which is the parameter tau-squared $\left(\tau^{2}\right)$, defined as the variance of the true effect sizes (the variance of the effect size parameters across the population of studies). According to [29] five ways of measuring heterogeneity are recognized: i) the Cochran's Q test [80], that is the sum of the squared deviation of each effect size from the mean, weighted by the inverse-variance for each study; ii) the $p$-value for any observed value of $Q$; iii) the between-studies variance $\left(T^{2}\right)$; iv) the between-studies standard deviation (T); v) the Higgin's index $\mathrm{I}^{2}$, or the ratio of true heterogeneity to total observed variation [81].

\subsection{Calculations}

The cases of single-lane, double-lane and turbo roundabouts were examined separately both for the critical and the followup headways. The groups of studies which have been subjected to meta-analysis varied for each case; each of these groups included a variable number of sub-groups (see tables hereinafter). Each sub-group contained on-field observations characterized by mean, standard deviation, and sample size; these data represented the data input of the meta-analysis. Note that the values of the critical headways considered in the calculations were obtained by the maximum likelihood method only [19].

Tables 4 and 5 show the outputs of the meta-analysis regarding the assessment of the critical and follow-up headways for the single-lane roundabouts; from left to right, we find the values of the variance that is referred to the summary effect, lower and upper limit, Z-values and $p$-values, the values of the $\mathrm{Q}$ test and the index $\mathrm{I}^{2}$. Since the Cochran's Q test [80] has to be used with caution as literature has repeatedly referred that has low power, the Higgin's index $I^{2}$ has been associated [29]; it measures the share of inconsistencies of the individual studies that cannot be explained by the sampling error. $\mathrm{I}^{2}$ represents only the proportion of variance that is true, but it says nothing about the absolute value of the variance.

In order to estimate what proportion of the observed variance reflects real differences among studies rather than random error, we start with $Q$, remove its dependence on the number of studies, and express the result through the ratio of excess dispersion to total dispersion (namely $I^{2}$ ). Importantly, $I^{2}$ is not directly affected by the number of studies in the analysis, whereas $Q$ depends on number of studies [29].
Moreover the index $I^{2}$ allows us to discuss the amount of variance on a relative scale: values on the order of $25 \%$, $50 \%$, and $75 \%$ might be considered as low, moderate, and high, respectively [81]. These benchmarks refer to the question of what proportion of the observed variation is real, and not to the variation on an absolute scale. Indeed, an $I^{2}$ value near $100 \%$ means only that most of the observed variance is real, but does not imply that the effects are dispersed over a wide range; they could fall in a narrow range but be estimated precisely $[29,81]$. It is noteworthy that, for the cases in Tables 4 and 5 , the $p$-value is approximately equal to zero, and the Higgin's index is around values of $1.2 \%$ for the critical headway and around values of $20.4 \%$ for the follow headway; both parameters confirm the absence of heterogeneity. Analogously the results of meta-analysis for double-lane and turbo roundabouts are shown in Tables 6, 7, 8, 9 and 10. In some case turbo roundabouts reveled moderate or high values of $I^{2}$; however, still few empirical studies to estimate the critical headway have been aimed at these roundabouts.

Tables 11 and 12 show a comparison between the summary effects and the weighted mean values (with regard to the sample size) of each study considered in the meta-analysis; it can be easily noted that the summary effect can be far from the single study estimate since it is independent and does not account for similar experimental data; however it gives, with greater power of the individual reviewed studies, a comprehensive measure, more accurate and reproducible, for the parameters of interest at each roundabout under examination.

\section{Conclusions}

With an ever-increasing plethora of studies, already published or being published in transportation engineering and behavioral science, it is challenging, if not impossible, for researchers to keep up with the literature on worldwide studies incorporating estimations of the major parameters for gap acceptance (namely the driver's critical headway and the followup headway), which are based on data collected in the field at existing roundabouts. Reviews conducted not only to synthesize the evidence on the effects of an intervention, or to support evidence-based policy or practice in road geometric design and evaluations of performance for roads and intersections, can represent therefore an extremely efficient method for obtaining the appropriate information on what has already been done well and what did not.

The primary objective of this research was to synthesize the measurements of critical and follow-up headways at roundabouts from the set of studies that were selected from the literature on roundabouts since this type of intersections can operate by gap acceptance rules. The goal of our analysis was to provide a synthesis from a body of data of critical and follow-up headways at single-lane, double-lane and turbo 
roundabouts from various and appropriately selected sources. In order to match the research goal, these data of critical and follow-up headways were compiled as the outcome of a systematic review which involved a detailed and comprehensive search strategy, the specification of the question to be addressed, the determination of the methods to be used for searching the literature and for including (or excluding) studies, and the specification of the methods to apply for performing the statistical analysis. This was done since the narrative reviews are often simply descriptive, do not consist of a systematic search of the literature derived a priori, and thereby often focus on a subgroup of studies in an area which is chosen basing on availability or author selection; moreover, narrative reviews can often include an element of selection bias.

Once formulated the review question, the inclusion and exclusion criteria were defined, the search strategy was developed to locate and select the studies, the data were extracted; therefore, the results were analyzed and interpreted.

Based on the considerations described above, a systematic literature review on critical and follow-up headway estimations at roundabouts was performed. Focus was made on studies which have addressed the problems of how to manage the randomness and the variability of values of critical and followup headways, and how to depict the distribution of these gap acceptance parameters. Thus, several studies and researches developed worldwide were examined, with reference to the countries where the roundabouts have an older tradition and schemes of turbo-roundabouts are already in operation; reference was also made to the countries where in more recent times roundabouts are becoming more and more common as intersection control and great emphasis has been given to geometric design and the appropriate use of the many roundabout installations progressively realized. Thus we were able to note dispersion in effect sizes, that is the effect size varied from one study to the next.

After this study activity, therefore, we focused on the metaanalysis of effect sizes, that is the analysis where each study yielded an estimate of the statistic chosen from the corresponding sample of data; thus we assessed the dispersion in these effects across studies and then computed the summary effect. This summary effect is nothing more than the weighted mean of the individual effects; moreover, the mechanism to assign the weights (and then the meaning of the summary effect) depends on the assumptions about the distribution of effect sizes from which the studies were sampled. Indeed, differently from the case of the fixed-effect model where all studies in the analysis share the same true effect size, and the summary effect is the estimate of this common effect size, under the random-effects model the true effect size varies from study to study, and the summary effect represents the estimate of the mean of the distribution of effect sizes. Thus, the single (quantitative) meta-analytic estimate, as shown in the Tables
11 and 12 for each parameter under examination, provides an accurate and reliable synthesis on the specific issue addressed, and gives, with greater power of the individual reviewed studies, a comprehensive measure, more accurate and reproducible, for the parameters of interest. The accurate estimation of critical and follow-up headways, in turn, make accurate the capacity calculations at roundabouts.

It is noteworthy that most theories related to gap acceptance behavior, as employed for unsignalized intersections and roundabouts, presume that drivers are consistent and uniform, so that the capacity estimations based on the gap acceptance models are performed assuming constant values for the critical and follow-up headways which represent an average value of all the observed drivers. As empirical evidence suggests, the quantification of the critical and follow-up headways can also vary based on the number of lanes, the diameter of the central island, the entry width, the presence (or not) of bunched vehicles in the circulating (major) streams, whereas at multi-lane roundabouts, the different demand scenarios can produce dominant and subdominant arrival flows at entries which in their turn can influence the predictions of the gap acceptance parameters. As a result, the capacity estimates based on the values of critical and follow-up headways also reflect average conditions. However, these assumptions could lead to erroneous or inflated capacity estimates due to the driver variability and heterogeneity.

Based on these considerations, a meta-analysis of effect size for each study, namely a statistical and quantitative analysis of the individual studies, was implemented as part of the literature review to assess the consistency of the effect across studies and to compute the summary effect. This quantitative meta-analytic estimate for each of the parameters of interest gave us a comprehensive measure for critical and follow-up headways more powerful than that given by each single study. This research was made for helping advance our specific interests about roundabouts and for designing further research on entry capacity estimations at roundabouts. It should be recalled that the critical and the follow-up headways are stochastically distributed and should be properly represented by a distribution of values, whereas for entry capacity calculations at steady-state conditions constant values for each of them are usually incorporated into capacity models. Analysts know that there is variability in gap acceptance parameters and often overlook what is the impact of the uncertainty on capacity analysis. Starting from the results derived from statistical treatment of the literature performed by the meta-analysis, one possible area of additional work is to assess the effect that the range of variation in the input parameters - namely the gap acceptance parameters - has on the estimation of entry capacity at roundabouts and to propose a framework for considering this issue in the operational analysis of different types of roundabouts as single-lane, multi-lane and turbo roundabouts. 
Open Access This article is distributed under the terms of the Creative Commons Attribution 4.0 International License (http:// creativecommons.org/licenses/by/4.0/), which permits unrestricted use, distribution, and reproduction in any medium, provided you give appropriate credit to the original author(s) and the source, provide a link to the Creative Commons license, and indicate if changes were made.

\section{References}

1. Luoma J, Sivak M (2012) Interactions of environmental and safety measures for sustainable road transportation. European Transport Research Review 4:189-199. doi:10.1007/s12544-012-0078-5

2. Rodegerdts L, Bansen J, Tiesler C, Knudsen J, Myers E, Johnson M, Moule M, Persaud B, Lyon C, Hallmark S, Isebrands H, Crown RB, Guichet B, O’Brien A (2010) National Cooperative Highway Research Program Report 672: Roundabouts: An Informational Guide, 2nd edn. Transportation Research Board of the National Academic. Washington. D.C, US

3. Moya-Gómez B, García- Palomares J C (2015) Working with the daily variation in infrastructure performance on territorial accessibility. The cases of Madrid and Barcelona. European Transport Research Review 7: 20. doi: 10.1007/s12544-015-0168-2

4. Gitelman V, Carmel R, Pesahov F (2014) The evaluation of safety efficiency of non-urban infrastructure improvements; a case-study. European Transport Research Review 6:477-491. doi:10.1007/ s12544-014-0145-1

5. Robinson B W, Rodegerdts L, Scarbrough W, Kittelson W, Troutbeck R, Brilon W, Bondzio L, Courage K, Kyte M, Mason J, Flannery A, Myers E, Bunker J, Jacquemart G (2000) Roundabouts: An Informational Guide. Report Federal Highway Administration - FHWA-RD-00-067. US Department of Transportation

6. Tollazzi T (2015) Alternative Types of Roundabouts: An Informational Guide. Springer Tracts on Transportation and Traffic 6. Springer-Verlag. Springer International Publishing, Switzerland

7. Fortuijn LGH, Harte VF (1997) Meerstrooksrotondes: verkenning can nieuwe vormen - Turbo-roundabouts: A well-tried concept in a new guise. Verkeerskundige werkdagen 1997. CROW Ede, The Netherlands

8. Mauro R (2010) Calculation of Roundabouts. Springer-Verlag, Berlin Heidelberg

9. Brilon $\mathrm{W}, \mathrm{Wu} \mathrm{N}$, Bondzio L (1997) Unsignalized intersections in Germany-a State of the Art. 3rd International Symposium on Intersections Without Traffic Signals, Portland, Oregon, USA, July 21-23, 1997

10. Bovy H, Dietrich K, Harmann A (1991) Guide Suisse des Giatoires. Lausanne, Switzerland

11. Kimber R M (1980) The traffic capacity of roundabouts. TRRL Laboratory Report 942, Berkshire, UK

12. GIRABASE (2008) Calculation of roundabout capacity. http:// www.certu.fr

13. Brilon $\mathrm{W}, \mathrm{Wu} \mathrm{N}$ (2001) Capacity at unsignalized intersections derived by conflict technique. Transportation Research Record 1776: $82-90$

14. Highway Capacity Manual (2000) Transportation Research Board Special Report 209, 3th edition

15. Al-Madani HMN (2013) Capacity of large dual and triple-lanes roundabouts during heavy demand conditions. Arabian Journal for Science and Engineering 38(3):491-505. doi:10.1007/s13369$012-0330-2$
16. Giuffrè $\mathrm{O}$, Granà $\mathrm{A}$, Marino $\mathrm{S}$ (2012) Comparing performances of turbo-roundabouts and double-lane roundabouts. Modern Applied Science 6(10):70-79. doi:10.5539/mas.v6n10p70

17. Zheng D, Chitturi M, Bill A, Noyce D A (2011) Comprehensive evaluation of Wisconsin roundabouts Volume 1: Traffic Operations. Wisconsin Traffic Operations and Safety Laboratory, Wisconsin, US, Available at http://wwwtopslabwiscedu/projects/4-10html Accessed 28 March 2013

18. Tian Z, Troutbeck R J, Kyte M, Brilon W, Vandehey M, Kittelson W, Robinson B (2000) A further investigation on critical gap and follow-up time. 4th International Symposium on Highway Capacity, Transportation Research Circular E-C018. Maui, Hawaii, June 27-July 1

19. Tian Z, Kyte W, Vandehey M, Robinson B, Kittelson W, Troutbeck RW, Brilon W (1999) Implementing the maximum likelihood methodology to measure driver's critical gap. Transportation Research Part A 33:187-197

20. Troutbeck R J (1992) Estimating the critical acceptance gap from traffic movements. Queensland University of Technology

21. Highway Capacity Manual (2010) Transportation Research Board. Special Report 209. 5th edition

22. Khatib Z, Kyte M (2000) Framework to consider the effect of uncertainty in forecasting the level of service of signalized and unsignalized intersections. 4th International Symposium on Highway Capacity, Transportation Research Circular E-C018. Maui, Hawaii, June 27-July 1

23. Kyte M, Tian Z, Mir Z, Hameedmansoor Z, Kittelson W, Vandehey M, Robinson B, Brilon W, Bondzio L, Wu N, Troutbeck R J (1996) NCHRP Web Document 5: Capacity and level of service at unsignalized intersections: Final Report Vol. 1: Two-Way Stop Controlled Intersections. TRB. National Research Council. Washington. DC

24. Troutbeck RJ (1986) Average delay at an unsignalized intersection with two major streams each having a dichotomized headway distribution. Transportation Science 20(4):272-286. doi:10.1287/trsc. 20.4.272

25. Troutbeck R J (1991) Recent Australian unsignalized intersection research and practices. Intersections without Traffic Signals II. Springer-Verlag (Werner Brilon. ed.): 238-257

26. Chalumuri RS, Yasuo A (2014) Modelling travel time distribution under various uncertainties on Hanshin expressway of Japan. European Transport Research Review 6:85-92. doi:10.1007/ s12544-013-0111-3

27. Grayman WM (2005) Incorporating uncertainty and variability in engineering analysis. Journal of Water Resources Planning and Management 131(3):158-160

28. Galvan JL (2012) Writing literature reviews, 5th edn. Pyrczak Publishing, Glendale, CA

29. Borenstein M, Hedges LV, Higgins JPT, Rothstein HR (2009) Introduction to meta-analysis. Wiley, Chichester, UK

30. Singh V, Sharma SK (2015) Fuel consumption optimization in air transport: a review, classification, critique, simple meta-analysis, and future research implications. European Transport Research Review 7:12. doi:10.1007/s12544-015-0160-x

31. Brilon W (2011) Studies on roundabouts in Germany: Lessons Learned. 3rd International TRB-roundabout Conference, Carmel, Indiana, May 2011

32. FGSV: Handbuch fuer die bemessung von Straßen (HBS: German Highway Capacity Manual). Forschungsgesellschaft für Straßenund Verkehrswesen (FGSV). (www.fgsv.de). Cologne, edition 2001

33. Tanner JC (1967) The capacity of an uncontrolled intersection. Biometrica 54(3/4):657-658

34. Brilon W, Koenig R, Troutbeck RJ (1999) Useful Estimation Procedures for Critical Gaps. Transportation Research Part A: 
Policy and Practice 33(3-4):161-186. doi:10.1016/S09658564(98)00048-2

35. BPS: Manual for the program KREISEL version 7, (www. bpsverkehr.de), 2011

36. Brilon W (2014) Roundabouts: a state of the art in Germany. 4th International TRB-roundabout Conference, Conference, Seattle, Washington, April 2014

37. Wu N (1997) An universal formula for calculating capacity at roundabouts. Research report of Institute for Traffic Engineering No.13, Ruhr-University Bochum, March 1997

38. Wu N (2012) Estimating distribution function of critical gaps at unsignalized intersections based on equilibrium of probabilities. Transportation Research Record 2286:49-55. doi:10. 3141/2286-06

39. Brilon W, Bondzio L, Weiser (2014) Experiences with TurboRoundabouts in Germany. 5th Rural Roads Design meeting, Copenhagen. http://nmfv.dk/wp-content/uploads/2014/04/ Experiences-with-Turbo-Roundabouts-in-Germany-BrilonBondzio-Weiser.pdf Accessed April 3-4, 2014

40. Leemann N, Santel G (2009) Two-lane roundabouts. 9th Swiss Transport Research Conference, Ascona, Sept 9-11, 2009

41. Brilon W (1988) Recent development in calculation methods for unsignalized intersections in West Germany. In: Brilon W (ed) Intersections without Traffic Signals. Springer-Verlag, Berlin Heidelberg, pp. 111-153

42. Hagring O, Rouphail N M, Sørensen H A (2003) Comparison of capacity models for two-lane roundabouts. 82nd TRB Annual Meeting, Washington, DC, USA, January 2003

43. Greibe P, La Cour Lund B (2010) Capacity of 2-lane roundabouts. 4th International Symposium on Highway Geometric Design, June 2nd-5th 2010 Valencia, Spain

44. Fortuijn LGH (2009) Turbo roundabout. Estimation of capacity. Transportation Research Record 2130(2009):83-92. doi:10.3141/ 2130-11

45. Gazzarri A, Martello MT, Pratelli A, Souleyrette R (2013) Gap acceptance parameters for HCM 2010 roundabout capacity model applications in Italy. Wit serifes on Transport systems \& traffic engineering 1:1-6

46. Ferrari P, Giannini F (1994) Ingegneria stradale: geometria e progetto di strade [Road engineering: geometry and road geometric design]. ISEDI, pp 228-230

47. Raff MS, Hart JW (1950) A volume warrant for urban stop signs. The Eno Foundation for Highway Traffic Control. Saugatuck, Conn, USA

48. Romano E (2004) Driver behaviour at the roundabouts: analysis and simulation. 2nd International SIIV Congress: New technologies and modeling tools for roads, Florence, Italy, October 2004

49. Nicolosi V, Crisalli U, D’Apuzzo M (2008) Le intersezioni a rotatoria: analisi teorico-sperimentale e modelli teorici per la stima della capacità [Roundabouts: theoretical and experimental analysis and models for capacity estimation]. $17^{\circ}$ Convegno Nazionale SIIV [17th National SIIV Conference], Enna, Italy, September 2008

50. Dawson R F (1969) The hypererlang probability distribution - a generalized traffic headway model. International Symposium on the Theory of Traffic Flow and Transportatio, Karlsruhe, Series Strassenbau und Strassenverkehrstechik 86

51. Siegloch W (1973) Die Leistungsermittlung an Knotenpunkten ohne Lichtsignalsteuerung (Capacity Calculations for Unsignalized Intersections), Series Strassenbau und Strassenverkehrstechnik 154, Bundesminister für Verkehr

52. De Luca M, Grossi R, Petitto S (2002) Studio del funzionamento delle rotatorie mediante la tecnica della simulazione: modello e verifiche sperimentali [Study of roundabout performances by simulation: model and experimental validation]. 1th International SIIV Conference, Parma, Italy, October 2002
53. Vasconcelos L, Bastos Silva A, Seco Á, Rouxinol G (2012) Estimation of critical headways at unsignalized intersections - a microscopic approach. Advances in Transportation Studies Special Issue 1:59-72

54. Polus A, Shiftan Y, Shmueli-Lazar S (2005) Evaluation of the waiting-time effect on critical gaps at roundabouts by a logit model. European Journal of Transport and Infrastructure Research 5(1):1-12

55. Vasconcelos L, Seco Á, Bastos Silva A (2013) Comparison of procedures to estimate critical headways at roundabouts. Promet Traffic \& Transportation 25(1):43-53. doi:10.7307/ptt.v25i1.1246

56. Troutbeck RJ (1993) Capacity and design of traffic circles in Australia. Transportation Research Record 1398:68-74

57. Troutbeck R J (1990) Traffic interactions at roundabouts. 15th ARRB Conference, Vol. 15-Part 5, Australia, 1990

58. Troutbeck RJ (1984) Capacity and Delays at Roundabouts-A Literature Review. Australian Road Research Board 14(4):205-216

59. Troutbeck R J (1985) Does gap acceptance theory adequately predict the capacity of a roundabout? 12th ARRB Conference, Australia, Vol. 12-Part 4: 62-75

60. Troutbeck R J (1992) Changes to Analysis and Design of Roundabouts Initiated in the Austroads Guide. 16th ARRB Conference, Vol. 16-Part 5, Australia, 1992

61. Rodegerdts L, Blogg M, Wemple E, Myers E, Kyte M, Dixon M, List G, Flannery A, Troutbeck R, Brilon W, Wu N, Persaud B, Lyon C, Harkey D, Carter D (2007) Roundabouts in the United States. National Cooperative Highway Research Program Report 572. Transportation Research Board of the National Academic. Washington. D.C., USA

62. Akcelik R (2007) A review of gap acceptance capacity models. 29th Conference of Australian Institute of Transport Research, Adelaide, Australia 5-7 December 2007, Revised 14 July 2011

63. Akcelik R (2008) Roundabouts in Australia. 2nd International TRB-Roundabouts Conference. Kansas City, MO, USA, 18-21 May 2008

64. Akçelik R, Chung E, Besley M (1998) Roundabouts: Capacity and Performance Analysis, Research Report ARR No 321, 2nd edn. ARRB Transport Research Ltd, Australias

65. Troutbeck RJ (1989) Evaluating the performances of a roundabouts. Special report SR 45 ARRB, Transport Research Ltd, Vermouth South, Australia

66. AUSTROROADS (1993) Roundabouts. Guide to traffic engineering practice Part 6. Association of State Australian state road and transport authorities, Sidney, Australia

67. Akcelik R (2011) An Assessment of the Highway Capacity Manual 2010 Roundabout Capacity Model. International TRB Roundabout Conference, Carmel, Indiana, USA, May 2011

68. Akcelik R (2011) Roundabout design and capacity analysis in Australia and New Zealand. International Roundabout Design and Capacity Seminar. 6th International Symposium on Highway Capacity and quality of service, Stockholm, Sweden, 1st July, 2011

69. Qu X, Zhang IJ, Wang S, Liu Z (2014) Modelling follow up time at a single-lane roundabout. Journal of Traffic and Transportation Engineering 1(2):97-102

70. Troutbeck RJ (1998) Background for HCM Section on Analysis of Performance of Roundabouts. Transportation Research Record 1646(1998):54-62

71. Li Z, De Amico M, Chitturi M V, Bill A R (2013) Calibrating Vissim roundabout model using a critical gap and follow-up headway approach. 16th Road Safety on Four Continents Conference, Beijing, China, 15-17 May 2013

72. Xu F, Tian Z (2008) Driver behavior and gap-acceptance characteristics at roundabouts in California. Transportation Research Record 2071(2008):117-124. doi:10.3141/2071-14

73. Abrams D S, Fitzpatrick C D, Tang Y, Knodler M A (2013) A spatial and temporal analysis of driver gap acceptance behavior at 
modern roundabouts. 92nd Annual Meeting of the Transportation Research Board, Washington, D.C. January, 2013

74. Mensah S, Eshragh S, Faghri A (2009) A critical Gap Analysis for Modern Roundabouts. 89th Annual Meeting of the Transportation Research Board, Washington, D.C. January, 2010

75. Dahl J, Lee C (2012) Empirical estimation of capacity for roundabouts using adjusted gap-acceptance parameters for trucks. Transportation Research Record 2312:34-45. doi:10. 3141/2312-04

76. Qu Z, Duan Y, Song X, Hu H, Liu H, Guan K (2014) Capacity prediction model based on limited priority gap-acceptance theory at multilane roundabouts. Mathematical Problems in Engineering 2014:1-12(Article ID 490280)
77. Guo R (2010) Estimating critical gap of roundabouts by different methods. 6th Advanced Forum on Transportation of China, IET publisher, Beijing, October 2010: 84:89. doi:10.1049/cp.2010.1107

78. Ashworth R (1970) The analysis and interpretation of gap acceptance data. Transportation Science 4(3):270-280. doi:10.1287/trsc.4.3.270

79. Manage S, Suzuki K, Nakamura H (2003) Performance analysis of roundabouts as an alternative for intersection control in Japan. Journal of the Eastern Asia Society for Transportation Studies 5: $871-883$

80. Cochran WG (1950) The comparison of percentages in matched samples. Biometrika 37(3/4):256-266. doi:10.1093/biomet/37.3-4. 256

81. Higgins J, Thompson SG, Deeks JJ, Altman DG (2003) Measuring inconsistency in meta-analyses. BMJ 327:557-560 